\title{
Recommended Guanidine Suppressor for the Next-Generation Caustic-Side Solvent Extraction Process
}

\section{January 2013}

Prepared by

Bruce A. Moyer, Lætitia H. Delmau, Nathan C. Duncan, Dale D. Ensor, Talon G. Hill, Denise L. Lee, Benjamin D. Roach, Frederick V. Sloop, Jr., and Neil J. Williams 


\title{
DOCUMENT AVAILABILITY
}

Reports produced after January 1, 1996, are generally available free via the U.S. Department of Energy (DOE) Information Bridge.

Web site http://www.osti.gov/bridge

Reports produced before January 1, 1996, may be purchased by members of the public from the following source.

\author{
National Technical Information Service \\ 5285 Port Royal Road \\ Springfield, VA 22161 \\ Telephone 703-605-6000 (1-800-553-6847) \\ TDD 703-487-4639 \\ Fax 703-605-6900 \\ E-mail info@ntis.gov \\ Web site http://www.ntis.gov/support/ordernowabout.htm
}

Reports are available to DOE employees, DOE contractors, Energy Technology Data Exchange (ETDE) representatives, and International Nuclear Information System (INIS) representatives from the following source.

Office of Scientific and Technical Information

P.O. Box 62

Oak Ridge, TN 37831

Telephone 865-576-8401

Fax 865-576-5728

E-mail reports@osti.gov

Web site http://www.osti.gov/contact.html

This report was prepared as an account of work sponsored by an agency of the United States Government. Neither the United States Government nor any agency thereof, nor any of their employees, makes any warranty, express or implied, or assumes any legal liability or responsibility for the accuracy, completeness, or usefulness of any information, apparatus, product, or process disclosed, or represents that its use would not infringe privately owned rights. Reference herein to any specific commercial product, process, or service by trade name, trademark, manufacturer, or otherwise, does not necessarily constitute or imply its endorsement, recommendation, or favoring by the United States Government or any agency thereof. The views and opinions of authors expressed herein do not necessarily state or reflect those of the United States Government or any agency thereof. 
Next-Generation CSSX Program

\section{RECOMMENDED GUANIDINE SUPPRESSOR FOR THE NEXT- GENERATION CAUSTIC-SIDE SOLVENT EXTRACTION PROCESS}

Bruce A. Moyer, Lætitia H. Delmau, Nathan C. Duncan, Dale D. Ensor, Talon G. Hill, Denise L. Lee, Benjamin D. Roach, Frederick V. Sloop, Jr., and Neil J. Williams

Date Published: January 2013

Prepared by

OAK RIDGE NATIONAL LABORATORY

Oak Ridge, Tennessee 37831-6283

managed by

UT-BATTELLE, LLC

for the

U.S. DEPARTMENT OF ENERGY

under contract DE-AC05-00OR22725 



\section{CONTENTS}

\section{Page}

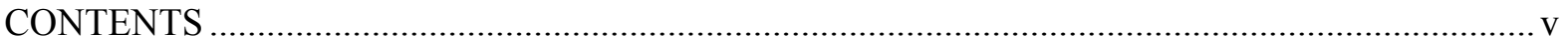

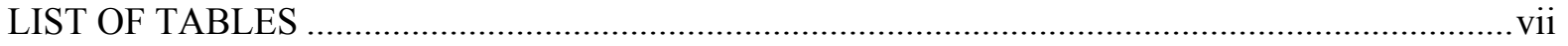

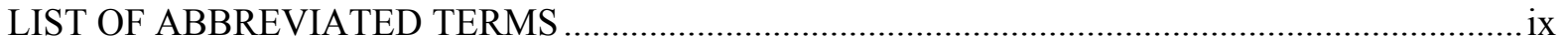

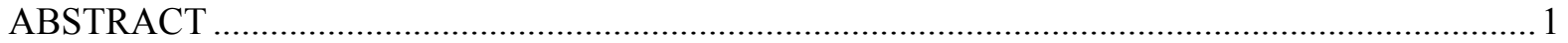

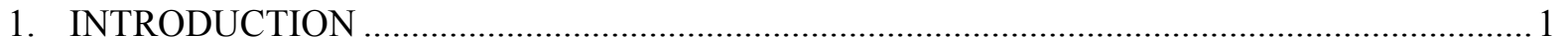

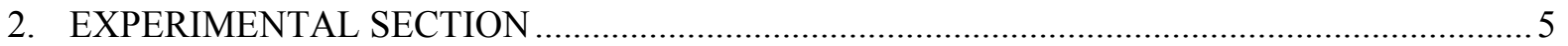

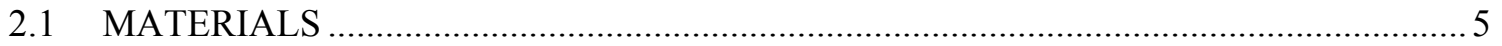

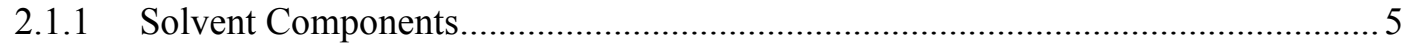

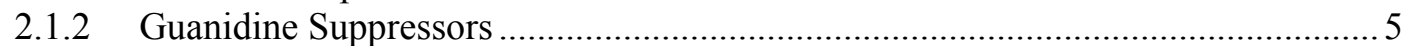

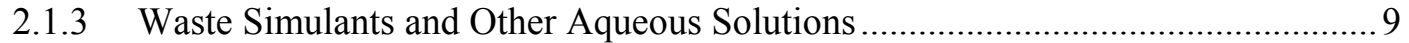

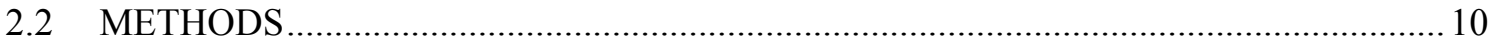

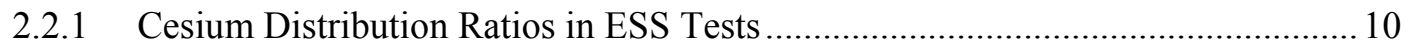

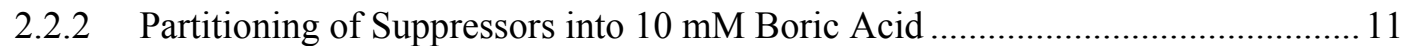

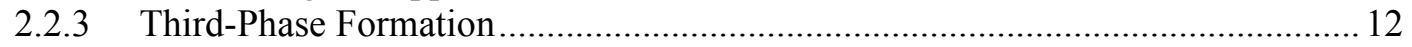

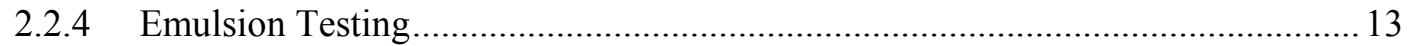

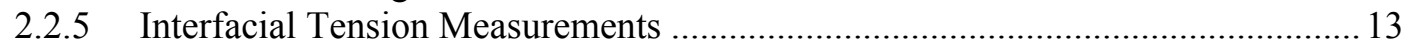

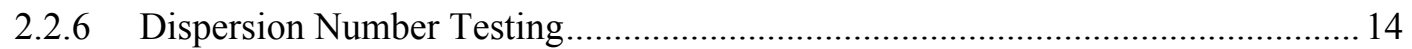

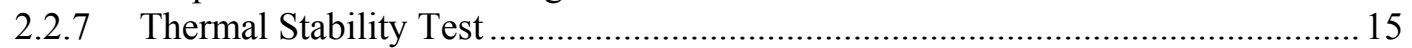

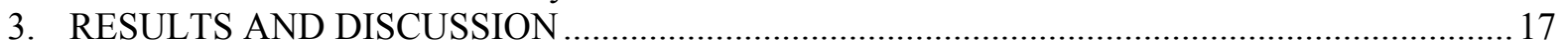

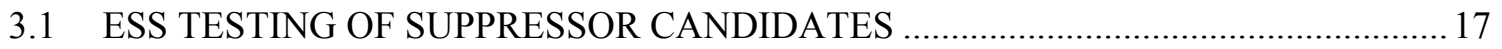

3.2 PARTITIONING OF SUPPRESSOR INTO BORIC ACID ....................................... 19

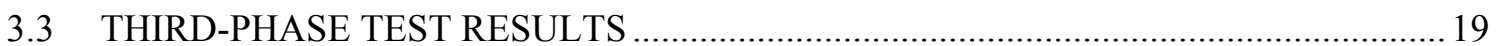

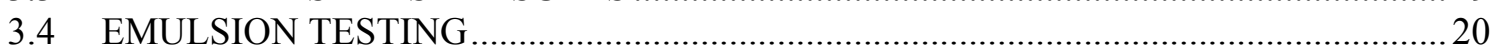

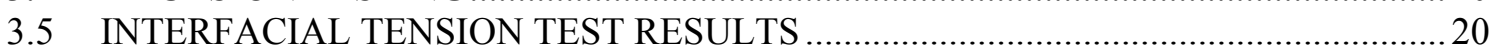

3.6 DISPERSION NUMBERS

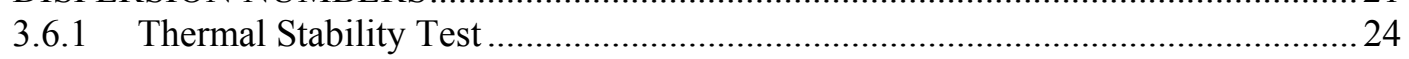

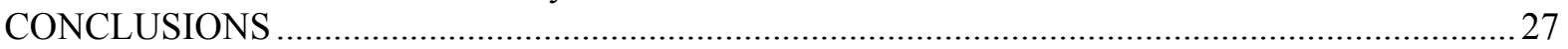

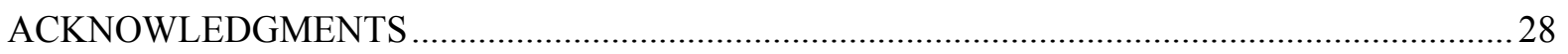

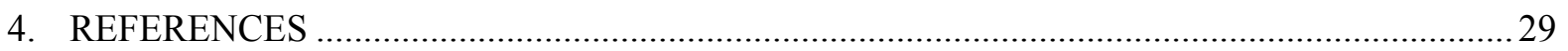





\section{LIST OF TABLES}

Table

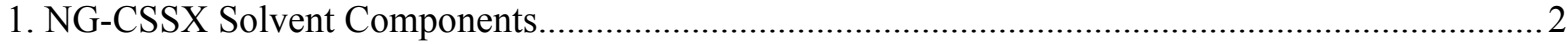

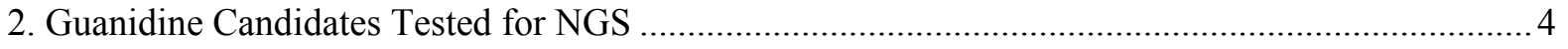

3. Aqueous Tank-Waste Simulants with Abbreviated Names Indicated........................................... 9

4. Cesium Distribution Ratios for ESS Batch Tests for Each of the Suppressor Candidates ................ 18

5. Cesium Distribution Ratios for ESS Batch Tests for Each of the Suppressor Candidates Stressed by

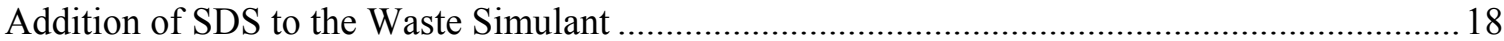

6. Guanidine Partition Ratios for NG-CSSX Solvent in Contact with $10 \mathrm{mM}$ Boric Acid Strip

Solution at $25^{\circ} \mathrm{C}$ 19

7. Third-Phase Test Results for Solvent Contacts with Boric Acid Strip Solution ............................20

8. Emulsion Test Results for NGS Candidate Solvents in Contact with $20 \mathrm{mM}$ Boric Acid...............20

9. Interfacial Tension of Candidate NG-CSSX Solvents Under ESS Conditions ...............................2 21

10. Dispersion Numbers for Various Guanidine Suppressors ......................................................... 23

11. Cesium Distribution Ratios for ESS Batch Tests for Thermally Treated Solvents Containing TiDG

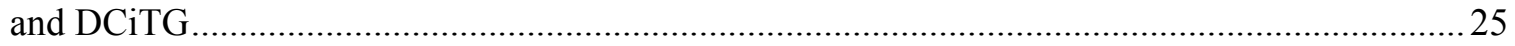





\section{LIST OF ABBREVIATED TERMS}

$\begin{array}{ll}\text { BiTABG } & N, N^{\prime} \text {-Bis(isotridecyl)- } N^{\prime \prime} \text {-(4-t-amylbenzyl)guanidine } \\ \text { Cs-7SB } & \text { Modifier 1-(2,2,3,3-tetrafluoropropoxy)-3-(4-sec-butylphenoxy)-2-propanol } \\ \text { CSSX } & \text { Caustic-Side Solvent Extraction } \\ \text { DCiTG } & N, N^{\prime} \text {-Dicyclohexyl- } N^{\prime \prime} \text {-isotridecylguanidine } \\ \text { DF } & \text { Decontamination factor } \\ \text { DOE } & \text { U.S. Department of Energy } \\ \text { ESS } & \text { Extract/scrub/strip } \\ \text { ES2S3 } & \text { Extract/scrub 2x/strip 3x } \\ \text { GC } & \text { Gas chromatography } \\ \text { HPLC } & \text { High performance liquid chromatography } \\ \text { LIX }{ }^{\circledR}-79 & \text { Commercial (Cognis) guanidine-containing extractant mixture } \\ \text { MaxCalix } & \text { Extractant 1,3-alt-25,27-bis(3,7-dimethyloctyl-1-oxy) calix[4]arene-benzocrown-6 } \\ \text { MCU } & \text { Modular CSSX Unit } \\ \text { NG-CSSX } & \text { Next Generation Caustic-Side Solvent Extraction } \\ \text { NGS } & \text { Next-generation solvent } \\ \text { NMR } & \text { Nuclear Magnetic Resonance } \\ \text { SDS } & \text { Sodium Dodecyl Sulfate } \\ \text { SRS } & \text { Savannah River Site } \\ \text { TiDG } & N, N^{\prime}, N^{\prime \prime}-\text { Tris(3,7-dimethyloctyl)guanidine } \\ \text { TnDDG } & N, N^{\prime}, N^{\prime \prime}-\text { Tris(n-dodecyl)guanidine } \\ \text { TnDG } & N, N N^{\prime},- \text { Tris(n-decyl)guanidine } \\ \text { TOA } & \text { Tri- }- \text {-octylamine } \\ \text { TsBPG } & N, N^{\prime}, N^{\prime \prime} \text {-Tris(sec-butylphenyl)guanidine }\end{array}$





\begin{abstract}
The guanidine recommended for the Next-Generation Caustic-Side Solvent Extraction (NG-CSSX) process is $N, N^{\prime}, N^{\prime \prime}$-tris(3,7-dimethyloctyl)guanidine (TiDG). Systematic testing has shown that it is significantly more lipophilic than the guanidine employed previously, $N, N^{\prime}$-dicyclohexyl- $N^{\prime \prime}-$ isotridecylguanidine (DCiTG), which is the active extractant in the commercial guanidine product LIX ${ }^{\circledR}$ 79, while not otherwise changing the solvent performance. Previous testing indicated that the extent of partitioning of the DCiTG suppressor to the aqueous strip solution is significantly greater than expected, potentially leading to rapid depletion of the suppressor from the solvent and unwanted organic concentrations in process effluents. Five candidate guanidines were tested as potential replacements for DCiTG. The tests included batch extraction with simulated waste and flowsheet solutions, third-phase formation, emulsion formation, interfacial tension, dispersion number (coalescence rate), and partition ratios of the guanidine between the solvent and aqueous strip solution. Preliminary results of a thermal stability test of the TiDG solvent at one-month duration indicated performance approximately equivalent to DCiTG. Two of the guanidines proved adequate in all respects, and TiDG was deemed slightly preferable vs. the next best performing guanidine BiTABG.
\end{abstract}

\title{
1. INTRODUCTION
}

This report presents the results obtained leading to a recommendation for an improved guanidine suppressor for the Next Generation Caustic-Side Solvent Extraction (NG-CSSX) process. The NG-CSSX process ${ }^{[1,2]}$ was designed to provide a step-jump improvement in waste decontamination factor (DF) and waste throughput vs. the CSSX process ${ }^{[3,4,5]}$ in the removal of cesium from legacy high-level salt waste stored in underground storage tanks in the U.S. Department of Energy (DOE) complex. Following initial results pointing to its feasibility ${ }^{[6,7,8]}$, the NG-CSSX process has been under development since 2010 under funding from the DOE Office of Environmental Management, Office of Technology Innovation and Development. To reach the target cesium decontamination and concentration factors $(\mathrm{DF}=40,000$ and $\mathrm{CF}=15)$ applicable to the Modular CSSX Unit $(\mathrm{MCU})^{[9,10,11]}$ at the Savannah River Site (SRS), a solvent containing $50 \mathrm{mM}$ of MaxCalix, $0.5 \mathrm{M}$ of modifier Cs-7SB, and $3 \mathrm{mM}$ of guanidine suppressor in Isopar ${ }^{\circledR} \mathrm{L}$ was adopted ${ }^{1}$. The structures of the next-generation solvent (NGS) components are shown in

Table 1 . The chemical role of each component has been described previously ${ }^{[1,3]}$. In particular, the ability to employ the extractant MaxCalix at $50 \mathrm{mM}$ vs $7 \mathrm{mM}$ for BOBCalixC6 in the CSSX process ${ }^{[3,5]}$ increased the cesium extraction strength and allowed the Cs-7SB modifier concentration to be decreased to $0.5 \mathrm{M}$. Although it is a minor component of the solvent, the suppressor is essential for stripping. In the 
CSSX process, tri- $n$-octylamine (TOA) is used as the suppressor, but it was found to be ineffective for stripping with the aqueous boric acid solution used in NG-CSSX ${ }^{[2]}$, requiring the use of a more basic suppressor. Stripping using the lipophilic guanidine DCiTG (Table 1), the active extractant in LIX ${ }^{\circledR} 79$, as the suppressor in the NGS was found to be two orders of magnitude more effective than stripping in $\operatorname{CSSX}^{[2,7]}$. How DCiTG functions remains incompletely understood, but it is thought that the guanidine ties up all extractable anions and thereby allows the cesium to be driven out of the solvent ${ }^{[12]}$. Results from real-waste batch tests ${ }^{[13]}$ and contactor testing ${ }^{[14]}$ have so far been promising. However, a potential issue with the guanidine suppressor DCiTG was identified, in which the partition ratio $P_{\text {Gua }}$ of DCiTG for contact of the solvent with the $10 \mathrm{mM}$ strip solution was found to be unexpectedly low ${ }^{[12]}$. The partition ratio $P_{\text {Gua }}$ is defined as the concentration of the guanidine in the organic phase divided by that in the aqueous phase at equilibrium. Its value was found to be $35 \pm 8^{[12]}$ vs. 14,300 for the suppressor TOA in the CSSX solvent in contact with the $1 \mathrm{mM} \mathrm{HNO}_{3} \mathrm{CSSX}$ strip solution ${ }^{[4]}$. A $P_{\text {Gua }}$ value of $>1000$ is desirable to avoid depletion of the suppressor as well as appreciable organic concentrations in aqueous process effluents.

\section{Table 1. NG-CSSX Solvent Components}

\begin{tabular}{|c|c|c|c|}
\hline Component & Name & Chemical Name $^{a}$ & Structure \\
\hline Extractant & MaxCalix & $\begin{array}{l}\text { 1,3-alt-25,27-Bis(3,7- } \\
\text { dimethyloctyl-1-oxy) } \\
\text { calix[4]arene-benzocrown-6 } \\
\text { MW 955.36 } \\
0.0500 \mathrm{M}(5.78 \mathrm{wt} \%)\end{array}$ & \\
\hline Modifier & Cs-7SB & $\begin{array}{l}\text { 1-(2,2,3,3-Tetrafluoropropoxy)-3- } \\
\text { (4-sec-butylphenoxy)-2-propanol } \\
\text { MW } 338.35 \\
0.500 \mathrm{M}(20.46 \mathrm{wt} \%)\end{array}$ & \\
\hline $\begin{array}{l}\text { Suppressor } \\
\text { (Original) }\end{array}$ & DCiTG & $\begin{array}{l}N, N \text {-Dicyclohexyl- } N " \text { - } \\
\text { isotridecylguanidine } \\
\text { MW } 405.73 \text { ( } 442.19 \text { for } \mathrm{HCl} \text { salt) } \\
0.0030 \mathrm{M}(0.15 \mathrm{wt} \%)(0.16 \mathrm{wt} \% \\
\text { for } \mathrm{HCl} \text { salt })\end{array}$ & \\
\hline $\begin{array}{l}\text { Suppressor } \\
\text { (Recommended } \\
\text { replacement) }\end{array}$ & TiDG & $\begin{array}{l}N, N^{\prime}, N^{\prime \prime}-\text { Tris }(3,7- \\
\text { dimethyloctyl)guanidine } \\
\text { MW } 479.89(516.35 \text { for } \mathrm{HCl} \text { salt }) \\
0.0030 \mathrm{M}(0.17 \mathrm{wt} \%)(0.19 \mathrm{wt} \% \\
\text { for } \mathrm{HCl} \text { salt })\end{array}$ & \\
\hline Diluent & Isopar L & $\begin{array}{l}\mathrm{C}_{12} \text {-isoparaffinic } \\
73.6 \mathrm{wt} \%\end{array}$ & \\
\hline
\end{tabular}


In 2012 development of the NGS continued with the goal of identifying a suitable replacement for DCiTG having a significantly higher $P_{\text {Gua }}$ value while otherwise not affecting solvent performance. Altogether, we examined five new guanidines in comparison to DCiTG used as a control. The guanidines tested are shown in Table 2 in the form of their $\mathrm{HCl}$ salts. All of the new guanidines have higher molecular weights than the control and are expected to have higher lipophilicity. Two of the candidates were designed to have aromatic groups to aid detection by UV for high performance liquid chromatography (HPLC) analysis. Three of the guanidines were symmetrical $N, N$ ', $N$ '-trialkylguanidines (i.e., the same alkyl group is placed on each nitrogen), two with straight chains and one with branched chains. The symmetrical structure would avoid scrambling of alkyl groups that we observed in the purification of DCiTG ${ }^{[14]}$ as well as offer some simplicity and lower cost in preparation. The three $N, N^{\prime}, N$ '-trialkylguanidines also have a defined molecular weight (an advantage for mass-spectrometric analysis), though the branching in TiDG, like that of DCiTG, gives a mixture of isomers that is somewhat inconvenient for chromatographic analysis. An all-alkyl structure also leads to the expectation of stability comparable to DCiTG along with equivalent extract/scrub/strip (ESS) behavior. At least for the $N, N^{\prime}, N^{\prime \prime}$-trialkylguanidines, the technical uncertainty in replacing DCiTG lies mostly in whether we might encounter unwanted changes in interfacial or phase behavior, which can be sensitive to the structure of substituent alkyl groups. Test solvents consisted of $0.050 \mathrm{M}$ MaxCalix, 0.50 M Cs-7SB modifier, and 0.0030 M guanidine in Isopar L diluent. Tests were designed to address the highest risks in replacing the guanidine and included partitioning to the boric acid strip solution, ESS using simulated SRS salt waste and flowsheet solutions, third-phase formation, emulsion formation, interfacial tension, and dispersion number (coalescence). It is also possible to report here the partial results for a thermal-stability test for one-month exposure of the TiDG solvent with SRS-15 simulant at $35^{\circ} \mathrm{C}$, the condition giving the most severe degradation in our previous tests with DCiTG ${ }^{[16]}$. 
Table 2. Guanidine Candidates Tested for NGS

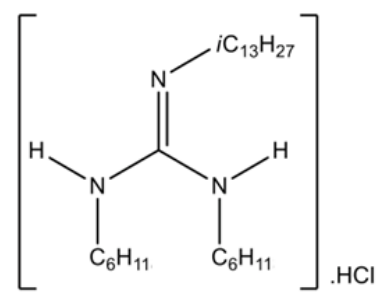

\section{DCiTG}

MW 442.19 (free base, 405.73)

(Control, current NGS baseline)

$N, N$-Dicyclohexyl- $N "$ "-isotridecylguanidine

Supplied by Marshallton

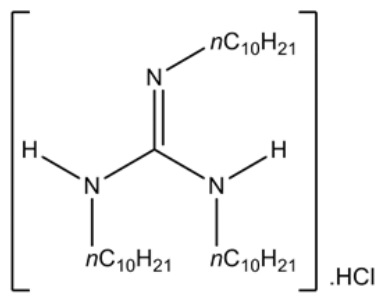

TiDG

MW 516.35 (free base, 479.89)

$N, N$ ', $N "$-Tris(3,7-dimethyloctyl)guanidine

or $N, N^{\prime}, N^{\prime \prime}$-Tris(isodecyl)guanidine

Supplied by Marshallton

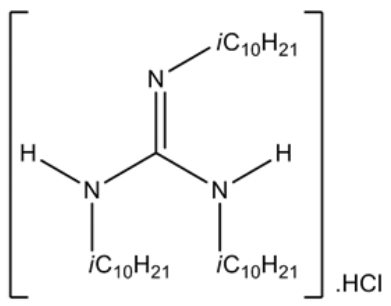

TnDG

MW 516.35 (free base, 479.89)

$N, N^{\prime}, N^{\prime \prime}$-Tris $(n$-decyl)guanidine

$\mathrm{TnDG}_{\mathrm{o}}$ - Synthesized at ORNL

$\mathrm{TnDG}_{\mathrm{M}}$-Supplied by Marshallton

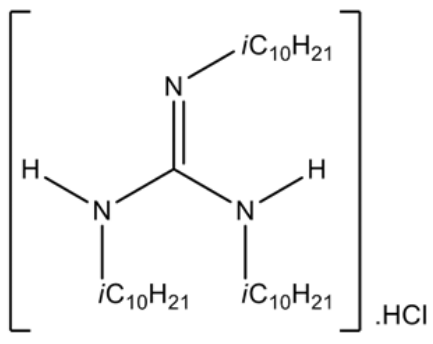

TnDDG

MW 600.52 (free base, 564.06)

$N, N^{\prime}, N^{\prime \prime}$-Tris(n-dodecyl)guanidine

Synthesized at ORNL

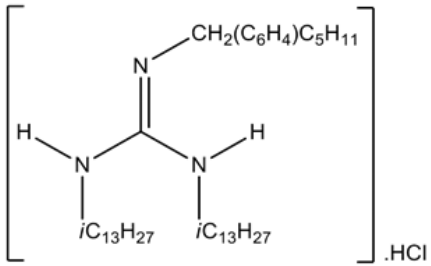

\section{BiTABG}

MW 620.51 (free base, 584.05)

$N, N^{\prime}$-Bis(isotridecyl)- $N "$-(4-t-amylbenzyl)guanidine

Synthesized by Marshallton

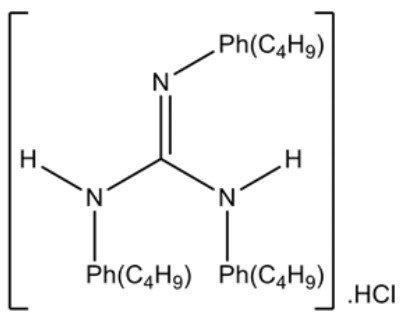

TsBPG

MW 492.16 (free base, 455.70)

$N, N^{\prime}, N^{\prime \prime}$-Tris(sec-butylphenyl)guanidine

Synthesized at ORNL 


\section{EXPERIMENTAL SECTION}

\subsection{MATERIALS}

\subsubsection{Solvent Components}

Solvent components were obtained from commercial sources and judged to be of adequate purity for use as received. 1-(2,2,3,3-Tetrafluoropropoxy),3-[4-(sec-butyl)phenoxy]-2-propanol (Cs-7SB modifier, Lot No. MOD2010-M-[2] or MOD2012-M-1) and 1,3-alt-25,27-bis(3,7-dimethyloctyl-1-oxy)calix[4]arenebenzocrown-6 (MaxCalix, Lot No. 71-061-15 or 79-239-1) were obtained from Marshallton Research, and Isopar L (Lot No. US67377A) was obtained from ExxonMobil. MaxCalix Lot No. 71-061-15 and Cs7SB Lot No. MOD2010-M-[2] were used for all experiments other than the interfacial-tension measurements. The suppressor candidates (see section 2.1.2) were used in the form of the $\mathrm{HCl}$ salts. Solvents were prepared by weighing appropriate amounts of extractant, modifier, and suppressor into volumetric flasks and diluting with Isopar L to the mark. Solutions were made assuming $100 \%$ purity. The major components are shown in Table 1.

\subsubsection{Guanidine Suppressors}

The guanidine suppressor candidates obtained from Marshallton were DCiTG (Lot. No. 79-042-2), TiDG

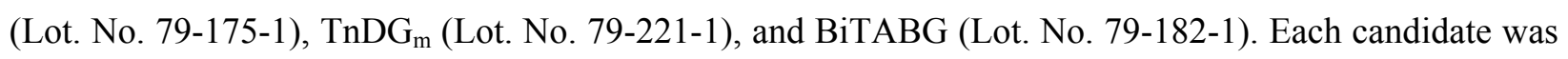
used as received [ $>95 \%$ purity, verified by gas chromatography (GC) and electrospray mass spectrometry upon receipt], without further purification. The TiDG (in $\mathrm{CDCl}_{3}$ ) was additionally checked by ${ }^{1} \mathrm{H}$ and ${ }^{13} \mathrm{C}$ NMR on a Varian VNMRS 500 NMR spectrometer, and found to be $\geq 99 \%$ pure.

Previously published procedures ${ }^{[17,18,19]}$, and modifications thereof, were followed in the synthesis of the remaining guanidines (see below). All reagents employed in the preparations were used as received from the suppliers without further purification unless otherwise noted. GC analyses were performed using a Hewlett Packard HP6850 Series GC System, fitted with a Agilent J\&W no. 122-1111E 15m x 0.250mm x $0.10 \mu \mathrm{m}$ narrow bore column with A DB-1HT stationary phase and using hydrogen as the carrier gas. Analyses were performed at $200-350{ }^{\circ} \mathrm{C}$ at $25{ }^{\circ} \mathrm{C} / \mathrm{min}$ with a 5 -min hold period. Proton and carbon NMR spectra were obtained in $\mathrm{CDCl}_{3}$ using a Bruker Avance III $400 \mathrm{MHz}$ spectrometer, unless otherwise noted. Chemical shifts were referenced to TMS at $0 \mathrm{ppm}$ for proton, and $\mathrm{CDCl}_{3}$ at $77.23 \mathrm{ppm}$ for carbon. 


\subsubsection{Generic preparation of $N, N^{\prime}, N^{\prime \prime}$-trialkylguanidine}

The generic synthetic method that was followed in the creation of these guanidine suppressors follows:

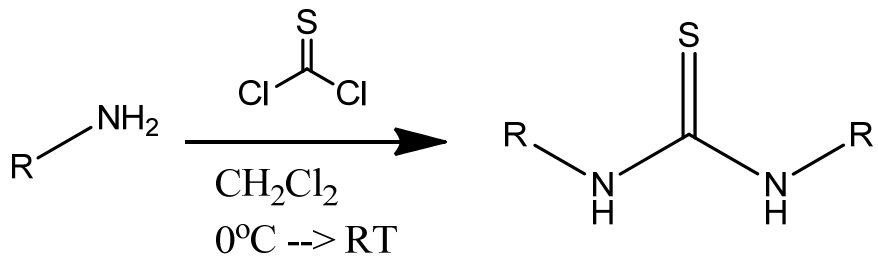

Dialkylthiourea. Two equivalents of amine are dissolved in dry methylene chloride in a septum-sealed flask and cooled in an ice water bath under an inert atmosphere. While stirring, thiosphosgene is slowly added by syringe and the reaction allowed warm to room temperature overnight. If the thiourea does not precipitate, it is isolated in vacuo and triturated with ether. Otherwise, the product is isolated by filtration and washed with diethylether.

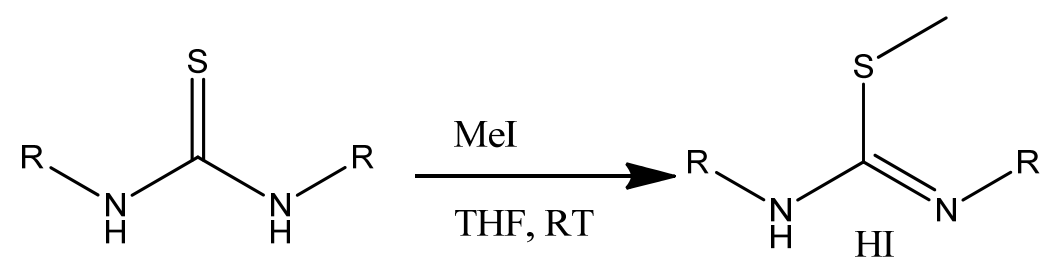

S-Methylthiouronium iodide. The purified di-alkylthiourea is dissolved in anhydrous THF (5 $\mathrm{g}$ in 75 $\mathrm{mL}$ ) under a nitrogen atmosphere to a septum-sealed flask stirred in a room-temperature water bath while excess methyl iodide (10 eq) is added by syringe. The reaction is allowed to proceed overnight, with stirring, and yields a yellow or orange-colored crude product.

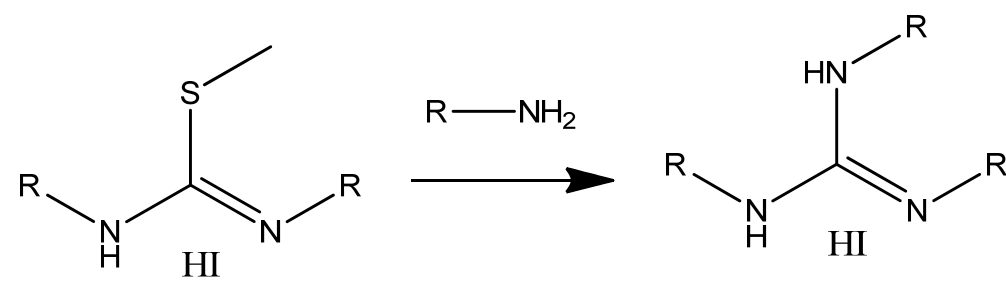

$N, N^{\prime}, N^{\prime}$-Trialkylguanidine. The crude reaction mixture from the thiouronium preparation is reduced in vacuo, and $5 \mathrm{~g}$ is then redissolved in about $50 \mathrm{~mL}$ of anhydrous methanol, ethanol, or chloroform with 1 eq of amine. It is important to use dry solvents in all steps to avoid low yields and side products. The reaction is refluxed until completion (indicated by GC), usually $24-48 \mathrm{~h}$ for alcohol solvent, or 3-4 days for chloroform. The solvent is then removed in vacuo, re-dissolved in $\mathrm{CHCl}_{3}$, and washed three times with equal volumes of $3 \mathrm{M} \mathrm{NaOH}$, followed twice with $1 \mathrm{M} \mathrm{NaOH}$, and finally three times with $1 \mathrm{M} \mathrm{HCl}$. 
The organic phase is washed with saturated $\mathrm{NaCl}$, dried over $\mathrm{MgSO}_{4}$, and reduced to dryness in vacuo to yield the trialkylguanidine hydrochloride salt. Product yields should be on the order of $>95 \%$ without further purification. Excess amine should be removed by Kugelrohr distillation.

\subsubsection{2 $N, N^{\prime}, N^{\prime \prime}-$ Tri-n-dodecylguanidine (TnDDG)}

$\boldsymbol{N}, \boldsymbol{N}$ '-Di-n-dodecylthiourea. $n$-Dodecylamine (5.0 g $27.0 \mathrm{mmol}, 2 \mathrm{eq})$ was dissolved, with stirring, in methylene chloride (ca. $100 \mathrm{~mL}$ ) under a dry nitrogen gas purge in an ice-water bath. Thiophosgene (1.03 $\mathrm{mL}, 13.5 \mathrm{mmol}, 1 \mathrm{eq}$ ) was added and the reaction allowed to come to room temperature and stirred for 12 hours. The thiourea was isolated by filtration and washed with diethyl ether (85-95\%).

$N, N^{\prime}$-Di-n-dodecyl-S-methylthiouronium iodide. $N, N^{\prime}$-Di- $n$-dodecylthiourea $(5.0 \mathrm{~g}, 12.1 \mathrm{mmol}, 1 \mathrm{eq})$ was placed in a septum-sealed flask under nitrogen purge. Anhydrous THF was added and the mixture stirred and cooled using a room-temperature water bath. Excess methyl iodide $(7.50 \mathrm{~mL}, 121 \mathrm{mmol}, 10$ eq) was added by syringe and the mixture stirred at room temperature overnight. (Caution: methyl iodide is toxic and a suspected carcinogen; handle appropriately.) The solvent was removed in vacuo and the crude product used without further purification.

$\boldsymbol{N}, \boldsymbol{N}^{\prime}, \boldsymbol{N}^{\prime \prime}$-Tri-n-dodecylguanidine. The crude $N, N^{\prime}$-di-n-dodecyl-S-methylthiouronium iodide was dissolved in anhydrous EtOH, $(50 \mathrm{~mL})$ to which $n$-dodecylamine amine (2.24 g, $12.1 \mathrm{mmol}, 1 \mathrm{eq})$ was added. The reaction was refluxed for $48 \mathrm{~h}$. The solvent was then removed in vacuo and the product redissolved in $\mathrm{CHCl}_{3}$ followed by washing three times with equal volumes of $3 \mathrm{M} \mathrm{NaOH}$, twice with $1 \mathrm{M}$ $\mathrm{NaOH}$, and finally 3 times with $1 \mathrm{M} \mathrm{HCl}$. The organic phase was washed with saturated $\mathrm{NaCl}$, dried over $\mathrm{MgSO}_{4}$, and the solvent removed in vacuo to yield the trialkylguanidine hydrochloride salt (80\%). The compound contains what is believed to be $N, N^{\prime}$-di-n-dodecylurea at about $58 \mathrm{~mol} \%$, putting the purity of the TnDDG at ca. $42 \mathrm{~mol} \%$. ${ }^{1} \mathrm{H}$ NMR (Varian VNMRS 500; $\mathrm{CDCl}_{3}$, peaks listed with the same chemical shift have a separation of $<0.05 \mathrm{ppm}): \delta 6.88$ (br t, $\left.3 \mathrm{H},-\mathrm{CNHCH}_{2^{-}}\right), 3.29\left(\mathrm{~m}, 6 \mathrm{H},-\mathrm{NHCH}_{2} \mathrm{CH}_{2}\right.$ ), 1.59 (p, $6 \mathrm{H},-\mathrm{NHCH}_{2} \mathrm{CH}_{2}-$ ), 1.38-1.18 (br m, overlaps with dodecylurea methylenes, $\left.54 \mathrm{H},-\mathrm{CH}_{2}\left(\mathrm{CH}_{2}\right)_{9} \mathrm{CH}_{3}\right), 0.84$ (t, overlaps with dodecylurea methyls, 9H, $\left.-\mathrm{CH}_{3}\right) ;{ }^{13} \mathrm{C} \mathrm{NMR}\left(\mathrm{CDCl}_{3}\right): \delta 155.7$ (C-(NH-) $\left.)_{3}\right), 42.8$ $\left(-\mathrm{NHCH}_{2} \mathrm{CH}_{2}-\right), 32.1\left(-\mathrm{NHCH}_{2} \mathrm{CH}_{2}-\right), 29.9,29.8,29.8,29.7,29.5,29.5,29.3,27.0,22.8\left(-\mathrm{CH}_{2}-\right.$ at chain positions 3-11), $14.3\left(-\mathrm{CH}_{3}\right)$.

\subsubsection{N, $N^{\prime}, N^{\prime \prime}-$ Tri-n-decylguanidine $\left(\operatorname{TnDG}_{0}\right)$}

1,3-Di-n-decylthiourea. $n$-Decylamine $(5.0 \mathrm{~g}, 31.7 \mathrm{mmol}, 2 \mathrm{eq})$ was dissolved with stirring in methylene chloride (ca. $100 \mathrm{~mL})$ under a dry nitrogen gas purge in an ice-water bath. Thiophosgene $(1.20 \mathrm{~mL}, 15.9$ 
mmol, 1 eq) was added and the reaction stirred overnight. The thiourea was isolated by filtration and washed with diethyl ether (90-100\%).

$\boldsymbol{N}, \boldsymbol{N}^{\prime}$-Di-n-decyl-S-methylthiouronium iodide. 1,3 -Di- $n$-decylthiourea $(5.0 \mathrm{~g}, 14.0 \mathrm{mmol}, 1 \mathrm{eq})$ was added to a nitrogen-purged septum-sealed flask. Anhydrous THF was added and the mixture stirred and cooled in a room-temperature water bath. Excess methyl iodide $(8.70 \mathrm{~mL}, 140 \mathrm{mmol}, 10 \mathrm{eq})$ was added by syringe and the reaction stirred at room temperature overnight. The solvent was removed in vacuo and the crude product used without further purification.

$\boldsymbol{N}, \boldsymbol{N}^{\prime}, \boldsymbol{N}^{\prime \prime}$-Tri-n-decylguanidine. The crude $N, N^{\prime}$-di- $n$-decyl-S-methylthiouronium iodide was redissolved in anhydrous $\mathrm{CHCl}_{3}(50 \mathrm{~mL})$, and $n$-decylamine amine $(2.20 \mathrm{~g}, 14.0 \mathrm{mmol}, 1 \mathrm{eq})$ was added. The reaction was refluxed for ca. $72 \mathrm{~h}$. The solvent was removed in vacuo, and the product was redissolved in $\mathrm{CHCl}_{3}$ and washed 3 times with equal volumes of $3 \mathrm{M} \mathrm{NaOH}$, followed twice with $1 \mathrm{M} \mathrm{NaOH}$ and finally three times with $1 \mathrm{M} \mathrm{HCl}$. The organic phase was washed with saturated $\mathrm{NaCl}$ and dried over $\mathrm{MgSO}_{4}$. The solvent was removed in vacuo to yield the trialkylguanidine hydrochloride salt (75-80\%). The purity is estimated at $80-85 \%$, based on NMR. ${ }^{1} \mathrm{H}$ NMR $\left(\mathrm{CDCl}_{3}\right): \delta 8.23\left(\mathrm{~s}, 3 \mathrm{H},-\mathrm{CNHCH}_{2}\right.$ ), 3.35 (q, 6H, $-\mathrm{NHCH}_{2} \mathrm{CH}_{2}$ ), 1.75 (m, 6H, $\left.-\mathrm{NHCH}_{2} \mathrm{CH}_{2}-\right), 1.27-1.19$ (br m, 42H, $\left.-\mathrm{CH}_{2}\left(\mathrm{CH}_{2}\right)_{7} \mathrm{CH}_{3}\right), 0.86$ (t, 9H, $\left.-\mathrm{CH}_{3}\right)$;

${ }^{13} \mathrm{C} \mathrm{NMR}\left(\mathrm{CDCl}_{3}\right.$, peaks listed with the same chemical shift have a separation of $\left.<0.05 \mathrm{ppm}\right): \delta 154.6(C$ $\left.(\mathrm{NH}-)_{3}\right), 42.8\left(-\mathrm{NHCH}_{2} \mathrm{CH}_{2}-\right), 32.0\left(-\mathrm{NHCH}_{2} \mathrm{CH}_{2}-\right), 29.8,29.8,29.5,29.5,29.3,26.9,22.8\left(-\mathrm{CH}_{2^{-}}\right.$at chain positions 3-9) $14.2\left(-\mathrm{CH}_{3}\right) .{ }^{13} \mathrm{C}$ chemical shift assignments were made by comparing the spectrum of this sample with the spectrum of a highly pure sample prepared by Marshallton.

\subsubsection{N, $N^{\prime}, N^{\prime \prime}-$ Tris(4-sec-butylphenyl)guanidine (TsBPG)}

$\boldsymbol{N}, \boldsymbol{N}^{\prime}$-Bis(1-sec-butylphenyl)thiourea. 4-sec-Butylaniline $(5.0 \mathrm{~g} 33.5 \mathrm{mmol}, 2 \mathrm{eq})$ was dissolved with stirring in methylene chloride (ca. $100 \mathrm{~mL}$ ) under a dry nitrogen gas purge in an ice-water bath. Thiophosgene $(1.26 \mathrm{~mL}, 16.75 \mathrm{mmol}, 1 \mathrm{eq})$ was added and the mixture permitted to stir overnight. The thiourea was isolated by filtration and washed with diethyl ether (95\%).

$N, N^{\prime}$-Bis(1-sec-butylphenyl)-S-methylthiouronium iodide. $N, N^{\prime}$-Bis(1-sec-butylphenyl)thiourea (5.0 g, $14.6 \mathrm{mmol}, 1 \mathrm{eq})$ was added to a nitrogen-purged flask to which anhydrous THF was added. The mixture was stirred and cooled using a room-temperature water bath. Excess methyl iodide $(9.0 \mathrm{~mL}, 146$ mmol, 10 eq) was added by syringe and the reaction stirred at room temperature overnight. The solvent was removed in vacuo and the crude product used without further purification.

$N, N^{\prime}, N^{\prime \prime}-$ Tris(4-sec-butylphenyl)guanidine. The crude $N, N$ '-bis(1-sec-butylphenyl)-S-methylthiouronium iodide was redissolved in $50 \mathrm{~mL}$ anhydrous $\mathrm{MeOH}$, and 4-sec-butylaniline $(2.17 \mathrm{~g}, 14.6$ mmol, 1 eq) was added. The mixture was refluxed for $48 \mathrm{~h}$, the solvent removed in vacuo, and the crude 
product redissolved in $\mathrm{CHCl}_{3}$. The solution was washed three times with equal volumes of $3 \mathrm{M} \mathrm{NaOH}$, twice with $1 \mathrm{M} \mathrm{NaOH}$, and finally three times with $1 \mathrm{M} \mathrm{HCl}$. The organic phase was washed with saturated $\mathrm{NaCl}$ and dried over $\mathrm{MgSO}_{4}$. Removal of the solvent in vacuo yielded the guanidine hydrochloride salt $(75 \%) .{ }^{1} \mathrm{H}$ NMR $\left(\mathrm{CDCl}_{3}\right): \delta 6.98\left(\mathrm{~d}, 6 \mathrm{H}, \mathrm{ArH}^{2,6}\right), 6.93\left(\mathrm{~d}, 6 \mathrm{H}, \mathrm{ArH}^{3,5}\right), 2.43(\mathrm{~m}, 3 \mathrm{H}$, $\left.-\mathrm{ArCHCH}_{3}\right), 1.44\left(\mathrm{~m}, 6 \mathrm{H},-\mathrm{CHCH}_{2} \mathrm{CH}_{3}\right), 1.08\left(\mathrm{~d}, 9 \mathrm{H},-\mathrm{CHCH}_{3}\right), 0.69\left(\mathrm{t}, 9 \mathrm{H},-\mathrm{CH}_{2} \mathrm{CH}_{3}\right) ;{ }^{13} \mathrm{C}$ NMR (Varian VNMRs 500; $\left.\mathrm{CDCl}_{3}\right): \delta 153.2\left(\mathrm{C}-(\mathrm{NH}-)_{3}\right), 146.8\left(\mathrm{Ar}^{4}\right), 132.4\left(\mathrm{Ar}^{1}\right), 128.0\left(\mathrm{Ar}^{3.5}\right), 124.2\left(\mathrm{Ar}^{2,6}\right), 41.2$ $\left(-\mathrm{CHCH}_{2} \mathrm{CH}_{3}\right), 31.1\left(-\mathrm{CHCH}_{2} \mathrm{CH}_{3}\right), 22.0\left(-\mathrm{CHCH}_{3}\right), 12.2\left(-\mathrm{CH}_{2} \mathrm{CH}_{3}\right)$. There appear to be two unidentified compounds containing the 4-sec-butylphenyl group present in the sample, as visualized by NMR. The major one could be 1,3-bis(4-sec-butylphenyl)urea, and the minor one could be 4-sec-butylaniline. For these compounds, the mole ratio of TsBPG to 1,3-bis(4-sec-butylphenyl)urea to 4-sec-butylaniline appears to be about $4: 2: 1$, indicating a TsBPG mole $\%$ purity of approximately $57 \%$.

\subsubsection{Waste Simulants and Other Aqueous Solutions}

The SRS-15 tank-waste simulant was prepared according to a method described previously ${ }^{[4,20]}$. It is designed to represent the average SRS tank-waste composition ${ }^{[20]}$ and is slightly modified to obtain the SRS-SDS simulant ${ }^{[12]}$ (see Table 3). Tracer ${ }^{137} \mathrm{Cs}$ was added to the simulants for ESS tests (4 $\mu \mathrm{L}$ spike from a $0.05 \mathrm{mCi} / \mathrm{mL}$ stock, $\mathrm{CsCl}$ in $\mathrm{H}_{2} \mathrm{O}$, Eckert \& Ziegler Isotope Products Inc., formally Isotope Products, Burbank, CA).

Table 3. Aqueous Tank-Waste Simulants with Abbreviated Names Indicated

\begin{tabular}{ll}
\hline \multicolumn{1}{c}{ Simulant } & \multicolumn{1}{c}{ Simulant description } \\
\hline SRS-15 & Average SRS salt waste simulant ${ }^{[9,19]}$ \\
SRS-SDS & SRS-15 with sodium dodecyl sulfate added to $5 \times 10^{-4} \mathrm{M}$ \\
\hline
\end{tabular}

Scrub solution $(0.025 \mathrm{M} \mathrm{NaOH})$ and other $\mathrm{NaOH}$ solutions were prepared by dilution of $1.0 \mathrm{M} \mathrm{NaOH}$ standard solution (Sigma Aldrich). Strip solution $\left(0.010 \mathrm{M} \mathrm{H}_{3} \mathrm{BO}_{3}\right)$ was made by dilution of a $0.1 \mathrm{M}$ $\mathrm{H}_{3} \mathrm{BO}_{3}$ stock solution prepared from lab-grade $\mathrm{H}_{3} \mathrm{BO}_{3}(>95.5 \%$, Sigma Aldrich). Solutions of $\mathrm{HCl}$ were made from 1.0 M HCl standard solution (Baker). Water for preparation of all aqueous solutions was first distilled and then deionized using a Milli- $\mathrm{Q}^{\circledR}$ gradient A10 filtering system equipped with a Quantum ${ }^{\mathrm{TM}}$ Ex Ultrapure Organex Cartridge $\left(18.2 \mathrm{M} \Omega \bullet \mathrm{cm}\right.$ at $25^{\circ} \mathrm{C}$, total organic content $\left.4 \mathrm{ppb}\right)$. 


\subsection{METHODS}

The solvents used in the following studies were comprised of $0.050 \mathrm{M}$ MaxCalix, $0.50 \mathrm{M}$ Cs-7SB modifier, and 0.0030 M suppressor in Isopar L. The solvent was prepared as described in section 2.1.1 and prewashed prior to use in the following manner: sequential contacts [single contact with an organicto-aqueous (O:A) phase ratio of 1:1] with $0.010 \mathrm{M} \mathrm{HCl}, \mathrm{H}_{2} \mathrm{O}$, then decreasing concentrations of $\mathrm{NaOH}$ (0.3 M, 0.1 M, 0.03 M, and 0.01 M), and then with $\mathrm{H}_{2} \mathrm{O}$ until the solution was $\mathrm{pH}$ neutral. It was noted that the organic phase was cloudy for TnDG and TnDDG on contacting the solvent with water following the wash step with $0.010 \mathrm{M} \mathrm{HCl}$.

\subsubsection{Cesium Distribution Ratios in ESS Tests}

Cesium distribution ratios in ESS tests were determined in a manner similar to that described previously ${ }^{[1,12]}$, with one extraction stage followed by two scrub stages using $0.025 \mathrm{M} \mathrm{NaOH}$ and three strip stages with $0.010 \mathrm{M} \mathrm{H}_{3} \mathrm{BO}_{3}$. The sequence, abbreviated as $\mathrm{ES}_{2} \mathrm{~S}_{3}$, was run in duplicate for each set of conditions. The organic and aqueous phases were contacted in polypropylene tubes $(50 \mathrm{~mL}$ for extraction and subsequently $15 \mathrm{~mL}$ for the scrubbing and stripping stages) sealed with Teflon tape to avoid organic loss via leakage, mounted by clips on a disk rotated at ca. $60 \mathrm{rpm}$ for $60 \mathrm{~min}$ for extractions and $45 \mathrm{~min}$ for scrubs and strips. The solutions were contacted inside an air-box maintained at a temperature of $25.0 \pm$ $0.5^{\circ} \mathrm{C}$. After the contacting period, the tubes were centrifuged for $5 \mathrm{~min}$ at $3000 \mathrm{rpm}$ at $25.0 \pm 0.5^{\circ} \mathrm{C}$. An appropriate aliquot of each phase was subsampled and counted for 5 min using a Packard Cobra II AutoGamma counter. A spike of ${ }^{137} \mathrm{Cs}\left(0.05 \mathrm{mCi} / \mathrm{mL}\right.$ stock, $\mathrm{CsCl}$ in $\mathrm{H}_{2} \mathrm{O}$, Eckert \& Ziegler Isotope Products Inc., formally Isotope Products, Burbank, CA) was added to the second and third aqueous strip solutions, owing to the low number of counts remaining after the each strip. To keep samples at the equilibration temperature, tubes were removed individually from the temperature-controlled centrifuge for subsampling. Cesium distribution ratios $\left(D_{\mathrm{Cs}}\right)$ are calculated as the ratio of organic- to aqueous-phase ${ }^{137} \mathrm{Cs}$ activity.

Based upon the agreement of duplicate samples run within the same set of measurements, the precision of $D_{\mathrm{Cs}}$ values within an ESS experiment run as described has generally been found ${ }^{[1]}$ to worsen in the steps of the sequence as follows: $\pm 5 \%$ (extraction and scrubs), $\pm 10 \%$ (first strip), and $\pm 30 \%$ (second and third strips). This duplicate precision correlates with volumetric precision $( \pm 3 \%)$ and counting precision, which is approximately $\pm 3 \%$ (extraction), $\pm 1 \%$ (scrubs), $\pm 10 \%$ (first strip), and $\pm 30-50 \%$ (second and third strips). Owing to the temperature sensitivity of cesium distribution (on the order of $10 \%$ change in $D_{\mathrm{Cs}}$ per ${ }^{\circ} \mathrm{C}{ }^{[1]}$ ), sample handling can introduce additional error. Thus, effective overall precision of extraction, 
scrub, and first strip $D_{\mathrm{Cs}}$ values is estimated to be on the order of $\pm 10 \%$. Each value presented in the tables in this report is the average of $D_{\mathrm{Cs}}$ values from duplicate ESS runs; the error given represents the standard deviation of the duplicates, the parenthetic number referring to the precision of the corresponding previous digit or, in a few cases, two digits [e.g., 2.11(3) $\times 10^{-1}$ means $0.211 \pm 0.003$ and $3.5(15) \times 10^{-4}$ means $0.00035 \pm 0.00015]$.

\subsubsection{Partitioning of Suppressors into $10 \mathrm{mM}$ Boric Acid}

NG-CSSX solvent samples were precontacted with SRS-15 at an O:A phase ratio of 1:4, then subsequently twice with $0.025 \mathrm{M} \mathrm{NaOH}$ at an O:A ratio of 3.75:1. The partitioning experiments were carried out by contacting the preconditioned solvent with $0.010 \mathrm{M}$ boric acid at O:A ratios of 1:10, 1:25, 1:50, and 1:100 in $50 \mathrm{~mL}$ polypropylene tubes sealed with Teflon tape to avoid organic loss via leakage, mounted by clips on a disk, and rotated at ca. $60 \mathrm{rpm}$ for $60 \mathrm{~min}$. The solutions were contacted inside an air-box maintained at a temperature of $25.0 \pm 0.5{ }^{\circ} \mathrm{C}$. After the contacting period, the tubes were centrifuged for $5 \mathrm{~min}$ at $3000 \mathrm{rpm}$ at $25.0 \pm 0.5{ }^{\circ} \mathrm{C}$ (Beckman Coulter refrigerated centrifuge). The organic layers were removed using Eppendorf micropipettes and briefly contacted with an equal volume of $0.1 \mathrm{M} \mathrm{NaOH}$ to ensure the guanidine suppressor was in its neutral form. The solvents were then separated again by centrifugation.

Chlorine-36 tracer was used to determine the concentration of the suppressors in the NG-CSSX solvents before and after the contacting with boric acid and $0.1 \mathrm{M} \mathrm{NaOH}$ described in the preceding paragraph. The solvent samples $(300 \mu \mathrm{L})$ were contacted with $\mathrm{HCl}(270 \mu \mathrm{L}, 0.01 \mathrm{M}$, diluted from a $0.1 \mathrm{M}$ standardized $\mathrm{HCl}$ stock solution) in $2.1 \mathrm{~mL}$ flip-top vials, spiked with $30 \mu \mathrm{L}$ of $0.01 \mathrm{mCi}{ }^{36} \mathrm{Cl}$ radiotracer and placed on a wheel and contacted on a Glas-col laboratory disk rotator in a custom-made air box (60 $\mathrm{rpm}, 25.0 \pm 0.5^{\circ} \mathrm{C}$ ) for $60 \mathrm{~min}$. The samples were subsequently centrifuged for $5 \mathrm{~min}$ at $3000 \mathrm{rpm}$ as above, ensuring complete phase separation. Aliquots of $150 \mu \mathrm{L}$ of each phase were pipetted into scintillation vials containing $5 \mathrm{~mL}$ of scintillation cocktail. The chloride distribution ratios were determined as the ratio of organic-to-aqueous phase ${ }^{36} \mathrm{Cl}$ activity, employing standard liquid scintillation counting. The chloride partition ratios $D_{\mathrm{Cl}}$ give the organic-phase chloride concentration through the relation

$[\overline{\mathrm{Cl}}]=\frac{D_{\mathrm{Cl}} C_{\mathrm{Cl}}}{\phi D_{\mathrm{Cl}}+1}$

where $C_{\mathrm{Cl}}$ is the initial aqueous chloride concentration (set by the standard $0.01 \mathrm{M} \mathrm{HCl}$ ), $\phi$ is the O:A phase ratio, and the overbar indicates an organic-phase species. The guanidine partition ratio $P_{\text {Gua }}$ is 
figured by equating the organic-phase chloride concentration to the organic-phase guanidine concentration before (pre) and after (post) contact with boric acid, as given in the following relation:

$$
P_{\text {Gua }}=\frac{[\overline{\mathrm{Gua}}]}{[\mathrm{Gua}]}=\frac{[\overline{\mathrm{Cl}}]_{\text {post }}}{\left([\overline{\mathrm{Cl}}]_{\mathrm{pre}}-[\overline{\mathrm{Cl}}]_{\mathrm{post}}\right) \phi}
$$

This method assumes that the chloride extracted by the solvent is completely due to the extraction of $\mathrm{HCl}$ by the guanidine. The validity of this assumption was confirmed by repeating the procedure with a control solvent sample having the NG-CSSX composition but without a guanidine. The organic-phase concentration of chloride in the control was found to be $1.6 \times 10^{-6} \mathrm{M}$.

Assuming that the contacting and counting procedure yields a value of $D_{\mathrm{Cl}}$ good to $\pm 5 \%$, the limit of quantitation of this method was assumed to correspond to a depletion of the organic-phase guanidine concentration of $\geq 10 \%$. From Eq. 2 , we have $P_{\text {Gua,lim }}=10 / \phi$. Thus, at an O:A ratio of 1:100 $(\phi=0.01)$, we can measure a guanidine partition ratio up to 1000 . However, a propagation-of-error analysis based on Eqs. 1 and 2 shows that the value of $P_{\text {Gua }}$ becomes increasingly uncertain as it approaches $P_{\text {Gua,lim. }}$.

\subsubsection{Third-Phase Formation}

Third-phase tests were performed by contacting aliquots of prewashed NG-CSSX solvent $(0.050 \mathrm{M}$ MaxCalix, 0.50 M Cs-7SB modifier, and $0.0030 \mathrm{M}$ suppressor) containing $3 \mathrm{mM}$ of each of following suppressor candidates, DCiTG, TnDG , TiDG, TnDDG, TsBPG, and BiTABG, with each of the aqueous process solutions (SRS-15 simulant, $0.025 \mathrm{M} \mathrm{NaOH}$, and $0.01 \mathrm{M} \mathrm{H}_{3} \mathrm{BO}_{3}$ ) in an ESS sequence at $10.0 \pm$ $0.1{ }^{\circ} \mathrm{C}$ for $45 \mathrm{~min}$. Thus, the solvents contacted with $0.025 \mathrm{M} \mathrm{NaOH}$ scrub solution were done so after being precontacted with SRS-15 at an O:A ratio of 1:4. The solvents contacted with $0.01 \mathrm{M} \mathrm{H}_{3} \mathrm{BO}_{3}$ strip solution were done so after being precontacted with SRS-15 at an O:A ratio of 1:4, then twice with $\mathrm{NaOH}$ at an O:A ratio of 3.75:1. The tests were conducted on a Glas-col laboratory disk rotator in a Fisher Scientific Low Temperature incubator using $2 \mathrm{~mL}$ Eppendorf flip-top polypropylene tubes containing an equal volume $(500 \mu \mathrm{L})$ of preconditioned solvent with each aqueous solution. A NIST traceable thermometer was placed inside the incubator. Each of the samples was visually inspected by two independent experimentalists for the presence of any third phase at the interface. 


\subsubsection{Emulsion Testing}

Prewashed NG-CSSX solvent samples (0.050 M MaxCalix, 0.50 M Cs-7SB modifier, and 0.0030 M suppressor) containing $3 \mathrm{mM}$ of each of following suppressor candidates, DCiTG, TnDG ${ }_{0}$, TiDG, TnDDG, TSBPG, and BiTABG, were precontacted with SRS-15 simulant at an O:A ratio of 1:4, then subsequently two times with $0.025 \mathrm{M} \mathrm{NaOH}$ at an O:A of 3.75:1. For emulsion testing, $1 \mathrm{~mL}$ aliquots of the preconditioned solvent were contacted three times with $1 \mathrm{~mL}$ boric acid $(0.02 \mathrm{M})$ using $2 \mathrm{~mL}$ Eppendorf flip-top polypropylene tubes. The phases were contacted by hand-vortexing using a VortexGenie 1 Touch Mixer at ambient temperature $\left(21-23{ }^{\circ} \mathrm{C}\right)$ followed by centrifugation for 5 min at 3000 rpm in a Beckman Coulter refrigerated centrifuge at $25^{\circ} \mathrm{C}$. The samples were visually inspected by two independent experimentalists for the presence of any emulsion after each contact.

\subsubsection{Interfacial Tension Measurements}

Interfacial tension measurements were made with a Cole-Palmer Surface Tensiomat 21 using the DuNouy ring method ${ }^{[21]}$ (platinum-iridium rings; $6 \mathrm{~cm}$ ). Prewashed solvent samples consisting of MaxCalix $(0.05$ $\mathrm{M})$, Cs7SB (0.5 M), and 0.003 $\mathrm{M}$ of suppressor (DCiTG, TiDG, TnDG $\mathrm{M}$, TnDDG, or BiTABG) were equilibrated in an ESS sequence with the process aqueous solutions SRS-15 simulant, $0.025 \mathrm{M} \mathrm{NaOH}$ (twice), and $0.010 \mathrm{M} \mathrm{H}_{3} \mathrm{BO}_{3}$ for $1 \mathrm{~h}$ (extraction) and $30 \mathrm{~min}$ (scrub and strip) inside of an air-box maintained at a temperature of $25.0 \pm 0.5^{\circ} \mathrm{C}$. After the contacting period, the tubes were centrifuged for 5 min at $3000 \mathrm{rpm}$ in a Beckman Coulter refrigerated centrifuge at $25{ }^{\circ} \mathrm{C}$ prior to separation. Interfacial tensions were determined for the solvents at the different stages of the ESS sequence. For example, the solvent used when measuring the interfacial tension for the first strip contact $\left(0.010 \mathrm{M} \mathrm{H}_{3} \mathrm{BO}_{3}\right)$ had been precontacted with SRS-15 simulant once, $\mathrm{NaOH} 0.025 \mathrm{M}$ twice, and once with $0.010 \mathrm{M} \mathrm{H}_{3} \mathrm{BO}_{3}$.

In the measurement of interfacial tension, a fresh sample of the aqueous solution $(20 \mathrm{~mL})$ was pipetted into a clean glass beaker $(50 \mathrm{~mL})$, and the DuNouy ring was then placed beneath the surface. The precontacted organic solution $(20 \mathrm{~mL})$ was carefully pipetted down the sides of the beaker onto the aqueous solution, thereby minimizing disturbance of the interface. The DuNouy ring was then slowly raised through the interface, allowing for the measurement of force needed for the ring to pass through, displayed on the tensiometer in dynes per centimeter squared $\left(\gamma / \mathrm{cm}^{2}\right)$. The ring was cleaned by gently rising with isopropanol followed by acetone to remove contaminants. After washing with the acetone and isopropanol, the rings were flame heated, removing possible organic contaminants from previous measurements. Each sample was measured in triplicate using the solvent recovered from the previous measurement to prevent the introduction of new contaminates. 


\subsubsection{Dispersion Number Testing}

The dispersion number, a dimensionless quantity that describes the tendency of a dispersion of two immiscible liquids to separate into its component phases ${ }^{[22]}$, was determined for the NG-CSSX solvent compositions containing selected guanidines at each point of an ESS sequence (Eq. 3). The dispersion number $N_{\mathrm{Di}}$ is determined by agitating the bulk solutions so as to generate a dispersion and measuring the break time $t_{\mathrm{b}}$, the time required for the two phases to coalesce, leaving a clear interface. In Eq. 3, the dispersion number is calculated from the thickness of the dispersion band reduced by a height $z$ at an acceleration of $a$. In the work reported, predetermined volumes of aqueous and organic solutions were placed into a $100 \mathrm{~mL}$ graduated cylinder, a ground glass stopper was placed into the cylinder, and the solutions were agitated to create the dispersion. In the extraction protocol, the ratio of solvent to SRS-15 simulant was 1:4. Due to the limited amount of simulant available, two extractions were performed on 48 $\mathrm{mL}$ of SRS-15 using $12 \mathrm{~mL}$ of the specified solvent each time. The two solvent lots were then combined for the subsequent scrubbing and stripping procedures. The O:A ratio in the scrub step was 3.75:1 and involved $6.4 \mathrm{~mL}$ of $0.025 \mathrm{M} \mathrm{NaOH}$ and $24 \mathrm{~mL}$ of solvent. Likewise, the four stripping steps were performed at and O:A ratio of 3.75:1 and involved $6.4 \mathrm{~mL}$ of $0.010 \mathrm{M} \mathrm{HBO}_{3}$ and $24 \mathrm{~mL}$ of solvent. Agitation was performed manually; the cylinder was vigorously shaken vertically for $20 \mathrm{~s}$, allowed to stabilize for $10 \mathrm{~s}$, and agitated for another $20 \mathrm{~s}$ interval, after which timing was initiated. In all cases, the method of agitation resulted in the entire depth of liquid becoming dispersed, and separation was timed until the interface between the two liquids returned to its original position and no individually distinguishable droplets were visible in either phase. The next determination was continued after complete transparency of both bulk phases was restored. Using the procedure described, $z$ becomes the total height of the liquid column in the graduated cylinder and $a$ is the gravitational constant. Where $N_{\mathrm{Di}}$ values were obtained under extraction, scrubbing, stripping, and washing conditions, the determinations were made sequentially, and the solvent was retained and reused in sequence in order to simulate solvent use in a full mass-transfer cascade.

$N_{\mathrm{Di}}=\frac{1}{t_{\mathrm{b}}} \sqrt{\frac{z}{a}}$

As indicated by the expression, the dispersion number is inversely proportional to the time required for a band of dispersed liquids to separate into its component solutions; hence, higher values of $N_{\mathrm{Di}}$ indicate greater ease of separation. 


\subsubsection{Thermal Stability Test}

NG-CSSX solvent obtained from ORNL, consisting of 0.050 M MaxCalix, 0.50 M Cs-7SB modifier, and 0.0030 M TiDG, was thermally treated at Tennessee Technological University by sustained contact with SRS-15 simulant. The samples were contained in sealed Teflon-FEP tubes, using Teflon (pipe thread) tape to avoid significant solvent loss over time. The initial masses of the sealed samples were taken, and any sample loss was determined via mass difference. It was assumed that any mass loss was due to the evaporation of Isopar L. Before testing, the samples were returned to their original mass by the addition of Isopar L. Altogether, 10 aliquots of NG-CSSX solvent, $8 \mathrm{~mL}$ each, were put into contact with SRS-15 simulant at an O:A ratio of 1:4 in separate tubes. An initial duplicate ESS run was completed immediately on two of the tubes to provide a baseline for freshly prepared, untreated NG-CSSX solvent ("0 month" samples). Four tubes were subjected to thermal treatment in a Lab Line Orbit Environ Shaker, Lab Line Instrument Inc, held at a constant temperature of $36.0 \pm 0.5^{\circ} \mathrm{C}$ and $250 \mathrm{rpm}$; two of these were withdrawn after 30 days ("1 month") and subjected to ESS analysis as described below; thermal treatment was continued for the other two tubes to be withdrawn and analyzed at a later time (not reported here). Four other tubes were stored in a refrigerator at $3{ }^{\circ} \mathrm{C}$ (not analyzed in this report). Solvent samples not contacted with SRS-15 simulant were set aside as follows: (a) in a refrigerator at $3{ }^{\circ} \mathrm{C}$; (b) in an incubator held at $36.0 \pm 0.5^{\circ} \mathrm{C}$; and (c) at room temperature. A portion of the solvent held at room temperature was withdrawn for ESS testing as the "1 month" sample for comparison with the sample thermally treated for one month.

Cesium distribution ratios were determined in duplicate $\mathrm{ES}_{2} \mathrm{~S}_{3}$ tests with simulants spiked with ${ }^{137} \mathrm{Cs}$ in a manner similar to that described previously ${ }^{[1,12]}$. Extraction steps consisted of NG-CSSX solvent being contacted with SRS-15 simulant waste with an O:A ratio of 1:4. The scrub steps consisted of the solvent being contacted with $25 \mathrm{mM} \mathrm{NaOH}$ with an O:A ratio of 3.75:1. The strip steps consisted of the solvent being contacted with $10 \mathrm{mM} \mathrm{H}_{3} \mathrm{BO}_{3}$ with an $\mathrm{O}$ :A ratio of 3.71:1. Unlike previously reported methods, here a final extraction contact was performed following the previous $\mathrm{ES}_{2} \mathrm{~S}_{3}$ sequence (to give an $\mathrm{ES}_{2} \mathrm{~S}_{3} \mathrm{E}$ sequence). For determination of the cesium distribution ratios, the organic and aqueous phases were contacted in Teflon-FEP centrifuge tubes $(50 \mathrm{~mL})$. These solutions were contacted on an orbital shaker and equilibrated at a temperature of $25.0 \pm 0.5^{\circ} \mathrm{C}$ in a constant-temperature water bath (ThermoScientific Refrigerated/Heater Bath Circulator). After the contacting period, the tubes were centrifuged for $10 \mathrm{~min}$ at $3000 \mathrm{rpm}$ (at ambient temperature) and returned to the constant temperature bath for at least $10 \mathrm{~min}$ to reequilibrate to $25^{\circ} \mathrm{C}$. An appropriate aliquot of each phase was subsampled and counted using a Packard Cobra II Auto-Gamma counter. A spike of ${ }^{137} \mathrm{Cs}$ was added $\left(4 \mu \mathrm{L}\right.$ of a $0.05 \mathrm{mCi} / \mathrm{mL}$ stock, $\mathrm{CsCl}$ in $\mathrm{H}_{2} \mathrm{O}$ ) 
to the second and third aqueous strip solutions, owing to the low number of counts remaining after the each strip and then respiked for the final extraction stage. 


\section{RESULTS AND DISCUSSION}

\subsection{ESS TESTING OF SUPPRESSOR CANDIDATES}

Standard ESS tests (see Table 4) showed that five guanidines, including DCiTG as a control, performed equivalently. Performance was also adequate when stressed with SDS (Table 6). The aromatic guanidine TsBPG failed to strip properly, likely owing to insufficient basicity. Tests were carried out under standard conditions at $25{ }^{\circ} \mathrm{C}$ with SRS-15 simulant $(\mathrm{O}: \mathrm{A}=4: 1), 0.025 \mathrm{M} \mathrm{NaOH}$ scrub solution $(\mathrm{O}: \mathrm{A}=3.75: 1)$, and $0.010 \mathrm{M}$ boric acid strip solution $(\mathrm{O}: \mathrm{A}=3.75: 1)$.

With the exception of TsBPG, the structure of the guanidine does not have an appreciable effect on the ability of the solvent to function properly in ESS tests starting with either SRS-15 or SRS-SDS (SRS-15 with added sodium dodecyl sulfate) simulants. Under the alkaline conditions of extraction and scrubbing, no effect was expected in either case, as the guanidines are expected to be in their neutral form. Under conditions of stripping, the test revealed TsBPG to perform poorly, eliminating it from further consideration. Because of the electron-withdrawing effect of the phenyl groups attached to the nitrogen atoms, the basicity of this guanidine is expected to be significantly reduced, thereby compromising its effectiveness as a suppressor.

Table 6 below shows a small effect of the surfactant SDS, confirming the effectiveness of the suppressing action of all guanidine candidates except TsBPG. Surfactant was earlier identified as a potential interferent in CSSX, and the mechanism of the role of TOA has been discussed ${ }^{[3,4]}$. In brief, the surfactant anion is more lipophilic than other anions in the system and thereby acts to make cesium more extractable, resisting stripping. The guanidine is expected to suppress the effect of surfactants in the same manner as TOA ${ }^{[12]}$, essentially by extracting the surfactant anion and a proton from the strip solution, thereby eliminating the surfactant from the cesium stripping equilibrium. The guanidine should release the surfactant in the wash and extraction sections of the flowsheet. A small increase in $D_{\mathrm{Cs}}$ can be detected in scrubbing (Table 6). The surfactant consistently raises $D_{\mathrm{Cs}}$ on stripping, but the effect is slight, and the scatter in the DCs values is increased. 
Table 4. Cesium Distribution Ratios for ESS Batch Tests for Each of the Suppressor Candidates ${ }^{a}$

\begin{tabular}{|c|c|c|c|c|c|c|c|c|c|c|}
\hline Stage & $\begin{array}{c}\begin{array}{c}\text { DCiTG } \\
\text { (Mar) }\end{array} \\
\end{array}$ & $\begin{array}{c}\text { DCiTG }^{\text {b }} \\
\text { (Mar) }\end{array}$ & $\begin{array}{l}\text { TiDG } \\
\text { (Mar) }\end{array}$ & $\begin{array}{l}\text { TiDG }^{\mathbf{b}} \\
\text { (Mar) }\end{array}$ & $\begin{array}{c}\text { TnDG }_{\mathbf{0}} \\
\text { (ORNL) }\end{array}$ & $\begin{array}{c}\text { TnDG }_{M}{ }^{b} \\
\text { (Mar) }\end{array}$ & $\begin{array}{l}\text { TsBPG } \\
\text { (ORNL) }\end{array}$ & $\begin{array}{l}\text { TnDDG } \\
\text { (ORNL) }\end{array}$ & $\begin{array}{c}\text { BiTABG } \\
\text { (Mar) }\end{array}$ & Average $^{c}$ \\
\hline Extract & $63(2)$ & $55.2(3)$ & $61(1)$ & $52.9(2)$ & $61.8(8)$ & $56.4(14)$ & $65(2)$ & $59.0(8)$ & $60(3)$ & $59(4)$ \\
\hline Scrub 1 & $2.9(2)$ & $2.7(2)$ & $2.9(3)$ & $2.41(2)$ & $3.1(4)$ & $2.2(6)$ & $3.3(2)$ & $2.9(4)$ & $3.0(3)$ & $2.8(3)$ \\
\hline Scrub 2 & $1.2(1)$ & $2.05(5)$ & $1.09(9)$ & $0.84(2)$ & $1.30(9)$ & $0.80(6)$ & $1.5(1)$ & $1.26(6)$ & $1.2(1)$ & $1.2(4)$ \\
\hline Strip 1 & $2.81(8) \times 10^{-3}$ & $1.6(1) \times 10^{-3}$ & $1.7(1) \times 10^{-3}$ & $1.1(2) \times 10^{-3}$ & $2.7(3) \times 10^{-3}$ & $1.03(2) \times 10^{-3}$ & $2.8(2) \times 10^{-1}$ & $2.6(4) \times 10^{-3}$ & $3.1(3) \times 10^{-3}$ & $2.1(8) \times 10^{-3}$ \\
\hline Strip 2 & $3.2(6) \times 10^{-4}$ & $3.7(2) \times 10^{-4}$ & $1.24(7) \times 10^{-4}$ & $2(1) \times 10^{-4}$ & $2.6(2) \times 10^{-4}$ & $1.07(2) \times 10^{-4}$ & $3.4(2) \times 10^{-1}$ & $3(1) \times 10^{-4}$ & $1.8(7) \times 10^{-4}$ & $2.3(9) \times 10^{-4}$ \\
\hline Strip 3 & $1.5(2) \times 10^{-4}$ & $2.7(7) \times 10^{-4}$ & $1.19(5) \times 10^{-4}$ & $1.1(9) \times 10^{-4}$ & $1.44(9) \times 10^{-4}$ & $3(2) \times 10^{-5}$ & $3.5(2) \times 10^{-1}$ & $1.4(1) \times 10^{-4}$ & $1.6(6) \times 10^{-4}$ & $1.4(6) \times 10^{-4}$ \\
\hline
\end{tabular}

${ }^{a}$ The aqueous phases were SRS-15 waste simulant (composition defined in Table 3 ) for extraction, $0.025 \mathrm{M}$ sodium hydroxide for scrubs, and $0.01 \mathrm{M}$ boric acid for strips. Solvent compositions consisted of 0.050 M MaxCalix, 0.50 M Cs-7SB, and 0.0030 M guanidine as indicated, in Isopar L diluent. The O:A ratios were 1:4 for extraction and 3.75:1 for both scrubbing and stripping stages. The contact temperature was maintained at $25 \pm 1{ }^{\circ} \mathrm{C}$. ${ }^{b} \mathrm{ESS}$ testing was performed on a separate occasion, the DCiTG (Mar) suppressor being used as a control. The contact temperature was maintained at $25.0 \pm 0.5{ }^{\circ} \mathrm{C}$. ${ }^{\mathrm{c}} \mathrm{Average}$ for all columns except that of TsBPG.

Table 5. Cesium Distribution Ratios for ESS Batch Tests for Each of the Suppressor Candidates Stressed by Addition of SDS to the Waste Simulant ${ }^{a}$

\begin{tabular}{|c|c|c|c|c|c|c|c|c|c|c|}
\hline Stage & $\begin{array}{c}\text { DCiTG } \\
\text { (Mar) }\end{array}$ & $\begin{array}{c}\text { DCiTG }^{b} \\
\text { (Mar) }\end{array}$ & $\begin{array}{l}\text { TiDG } \\
\text { (Mar) }\end{array}$ & $\begin{array}{l}\text { TiDG } \\
\text { (Mar) }\end{array}$ & $\begin{array}{l}\text { TnDG }_{0} \\
\text { (ORNL) }\end{array}$ & $\begin{array}{c}\text { TnDG }_{M}{ }^{b} \\
\text { (Mar) }\end{array}$ & $\begin{array}{c}\text { TsBPG } \\
\text { (ORNL) }\end{array}$ & $\begin{array}{l}\text { TnDDG } \\
\text { (ORNL) }\end{array}$ & $\begin{array}{c}\text { BiTABG } \\
\text { (Mar) }\end{array}$ & Average $^{c}$ \\
\hline Extract & $61(4)$ & $60.8(6)$ & $58.6(1)$ & $57.5(6)$ & $60(2)$ & $56(1)$ & $62.7(8)$ & $59.4(7)$ & $60.0(8)$ & $59(2)$ \\
\hline Scrub 1 & $3.7(1)$ & $3.8(2)$ & $3.9(2)$ & $4(1)$ & $4.6(1)$ & $3.0(4)$ & $4.2(1)$ & $4.2(3)$ & $4.1(1)$ & $3.9(5)$ \\
\hline Scrub 2 & $2.04(3)$ & $1.9(2)$ & $2.2(2)$ & $1.6(1)$ & $3.1(4)$ & $1.1(1)$ & $2.71(7)$ & $2.7(8)$ & $2.5(2)$ & $2.1(6)$ \\
\hline Strip 1 & $4.7(3) \times 10^{-3}$ & $3.3(2) \times 10^{-3}$ & $3.4(4) \times 10^{-3}$ & $2.2(3) \times 10^{-3}$ & $7.1(4) \times 10^{-3}$ & $1.33(4) \times 10^{-3}$ & $1.0(5)$ & $8.3(2) \times 10^{-3}$ & $6.8(3) \times 10^{-3}$ & $5(3) \times 10^{-3}$ \\
\hline Strip 2 & $3.9(8) \times 10^{-4}$ & $5.7(9) \times 10^{-4}$ & $1.83(1) \times 10^{-4}$ & $2.16(1) \times 10^{-4}$ & $4(1) \times 10^{-4}$ & $6(6) \times 10^{-5}$ & $1.2(4)$ & $4.3(5) \times 10^{-4}$ & $2.60(8) \times 10^{-4}$ & $3(2) \times 10^{-4}$ \\
\hline Strip 3 & $3.5(4) \times 10^{-4}$ & $2.79(8) \times 10^{-4}$ & $1.3(1) \times 10^{-4}$ & $1.73(5) \times 10^{-4}$ & $5.3(7) \times 10^{-4}$ & $1.6(7) \times 10^{-4}$ & $1.2(2)$ & $4.76(9) \times 10^{-4}$ & $2.1(1) \times 10^{-4}$ & $3(2) \times 10^{-4}$ \\
\hline
\end{tabular}

${ }^{a}$ The aqueous phases were SRS-SDS waste simulant (composition defined in Table 3) containing 0.01 M sodium dodecyl sulfate for extraction, $0.025 \mathrm{M}$ sodium hydroxide for scrubs, and 0.01 M boric acid for strips. Solvents consisted of 0.050 M MaxCalix, 0.50 M Cs-7SB modifier, and 0.0030 M guanidine as indicated, in Isopar L diluent; source of guanidine is either ORNL or Marshallton (Mar). The O:A ratios were 1:4 for extraction and 3.75:1 for both scrubbing and stripping stages. The contact temperature was maintained at $25 \pm 1{ }^{\circ} \mathrm{C}$. ${ }^{b} \mathrm{ESS}$ testing was performed on a separate occasion, the DCiTG (Mar) suppressor being used as a control. The contact temperature was maintained at $25.0 \pm 0.5^{\circ} \mathrm{C}$. ${ }^{\mathrm{c}}$ Average for all columns except that of TsBPG. 


\subsection{PARTITIONING OF SUPPRESSOR INTO BORIC ACID}

All guanidine candidates (except for TsBPG, which wasn't tested) were found to have higher partition ratios $P_{\text {Gua }}$ for NG-CSSX solvents in contact with boric acid strip solution than that of the DCiTG control. The guanidine candidates all possess higher molecular weights due to their overall larger hydrocarbon substituents as compared with DCiTG, and they are therefore expected to exhibit higher lipophilicity. The worst loss of guanidine in the flowsheet is expected to occur in the strip section, where the guanidine can become protonated, becoming somewhat aqueous soluble. The low value of $P_{\text {Gua }}$ for DCiTG under these conditions was unexpected and is thought to be related to the inability of borate to be extracted by the guanidine, drawing the protonated guanidine into the aqueous phase ${ }^{[12]}$. As shown in Table 6, all of the guanidine candidates proved to be superior to DCiTG with regards to lipophilicity. The method used to determine $P_{\text {Gua }}$ was an indirect extraction of $\mathrm{HCl}$ traced with chlorine-36, which by the difference in extraction of $\mathrm{HCl}$ before and after a partition contact of the solvent with boric acid at a low O:A ratio down to $1: 100$ gives $P_{\text {Gua }}$ (see Experimental Section). The limit of quantitation was estimated to be $P_{\text {Gua }}<1000$. As may be seen in Table 6, TiDG and BiTABG both exceeded this limit. Interestingly, TnDDG gave a lower $P_{\text {Gua }}$ value than the smaller-chain analog TnDG, which remains unexplained. It may have to do with aqueous micellation or other interfacial behavior not seen with the branched-chain guanidines TiDG and BiTABG. However, the behavior could also be due to the low purity of the samples of $\mathrm{TnDG}_{\mathrm{o}}$ and TnDDG that were used (see Experimental Section).

Table 6. Guanidine Partition Ratios for NG-CSSX Solvent in Contact with $10 \mathrm{mM}$ Boric Acid Strip Solution at $25{ }^{\circ} \mathrm{C}$

\begin{tabular}{lc}
\hline Guanidine & $\boldsymbol{P}_{\text {Gua }}$ \\
\hline DCiTG & $30.2 \pm 1.5$ \\
TiDG & $>1000$ \\
TnDG $_{\mathrm{o}}$ & $480 \pm 250$ \\
TnDDG & $100 \pm 11$ \\
BiTABG & $>1000$ \\
\hline
\end{tabular}

\subsection{THIRD-PHASE TEST RESULTS}

Visual tests of the six solvents in contact with SRS-15, scrub solution, and strip solution at $10{ }^{\circ} \mathrm{C}$ did not indicate any evidence for third-phase formation under potential process conditions (Table 7). Thirdphase formation occurs under certain loading conditions for almost all solvent-extraction systems. It cannot be tolerated in engineering equipment, and thus, it is essential to confirm that there is no potential for its occurrence under anticipated NG-CSSX processing conditions. Since the formation of third phases in the CSSX solvent has been associated primarily with potassium extraction by the calixarene, it 
was considered unlikely that the guanidine choice would play a role in third-phase formation in extraction or scrubbing. The new boric acid stripping chemistry, however, necessitated a test to eliminate potential risk, which was a simple visual check under ESS conditions. The test revealed no evidence for third-phase formation under any process conditions.

Table 7. Third-Phase Test Results for Solvent Contacts with Boric Acid Strip Solution ${ }^{a}$

\begin{tabular}{lcccccc}
\hline \multicolumn{1}{c}{ Stage } & DCiTG & TiDG & TnDG $_{\mathbf{0}}$ & TsBPG & TnDDG & BiTABG \\
\hline Extract (SRS-15 simulant) & $\mathrm{N} / \mathrm{O}$ & $\mathrm{N} / \mathrm{O}$ & $\mathrm{N} / \mathrm{O}$ & $\mathrm{N} / \mathrm{O}$ & $\mathrm{N} / \mathrm{O}$ & $\mathrm{N} / \mathrm{O}$ \\
Scrub $(\mathrm{NaOH}, 25 \mathrm{mM})$ & $\mathrm{N} / \mathrm{O}$ & $\mathrm{N} / \mathrm{O}$ & $\mathrm{N} / \mathrm{O}$ & $\mathrm{N} / \mathrm{O}$ & $\mathrm{N} / \mathrm{O}$ & $\mathrm{N} / \mathrm{O}$ \\
Strip $\left(\mathrm{H}_{3} \mathrm{BO}_{3}, 10 \mathrm{mM}\right)$ & $\mathrm{N} / \mathrm{O}$ & $\mathrm{N} / \mathrm{O}$ & $\mathrm{N} / \mathrm{O}$ & $\mathrm{N} / \mathrm{O}$ & $\mathrm{N} / \mathrm{O}$ & $\mathrm{N} / \mathrm{O}$ \\
\hline
\end{tabular}

${ }^{a}$ Solvents consisted of $0.050 \mathrm{M}$ MaxCalix, 0.50 M Cs-7SB modifier, and $0.0030 \mathrm{M}$ guanidine as indicated, in Isopar L diluent. The O:A ratios were 1:1 for all stages. The contact temperature was maintained at $10 \pm 1{ }^{\circ} \mathrm{C}$. $\mathrm{N} / \mathrm{O}=$ no third phase observed.

\subsection{EMULSION TESTING}

Emulsion tests for the solvents in contact three times with process solutions and three stripping contacts with $0.020 \mathrm{M}$ boric acid were also negative. Like third-phase formation, any tendency to form an emulsion under process conditions presents a risk of process upset. Emulsions have been observed in repeated stripping contacts using DCiTG solvent systems if the aqueous boric acid concentration is raised to $0.1 \mathrm{M}$, especially if the guanidine concentration is raised higher than $10 \mathrm{mM}{ }^{[23]}$. Given the unknown interfacial behavior of the different guanidines, it was deemed prudent to include a check for emulsion formation in the present series of development tests. Since it is possible that a future flowsheet modification could employ a higher boric acid concentration than the currently used $10 \mathrm{mM}$, the test employed $20 \mathrm{mM}$ boric acid, a more severe test than would be the case with $10 \mathrm{mM}$ boric acid. As shown in Table 8, no observation of emulsion formation was made in a series of ESS contacts at $25^{\circ} \mathrm{C}$.

Table 8. Emulsion Test Results for NGS Candidate Solvents in Contact with 20 mM Boric Acid ${ }^{a}$

\begin{tabular}{ccccccc}
\hline Stage & DCiTG & TiDG & TnDG $_{\mathbf{0}}$ & TsBPG & TnDDG & BiTABG \\
\hline Contact 1 & $\mathrm{~N} / \mathrm{O}$ & $\mathrm{N} / \mathrm{O}$ & $\mathrm{N} / \mathrm{O}$ & $\mathrm{N} / \mathrm{O}$ & $\mathrm{N} / \mathrm{O}$ & $\mathrm{N} / \mathrm{O}$ \\
Contact 2 & $\mathrm{~N} / \mathrm{O}$ & $\mathrm{N} / \mathrm{O}$ & $\mathrm{N} / \mathrm{O}$ & $\mathrm{N} / \mathrm{O}$ & $\mathrm{N} / \mathrm{O}$ & $\mathrm{N} / \mathrm{O}$ \\
Contact 3 & $\mathrm{~N} / \mathrm{O}$ & $\mathrm{N} / \mathrm{O}$ & $\mathrm{N} / \mathrm{O}$ & $\mathrm{N} / \mathrm{O}$ & $\mathrm{N} / \mathrm{O}$ & $\mathrm{N} / \mathrm{O}$ \\
\hline${ }^{a}$ So
\end{tabular}

${ }^{a}$ Solvents consisted of 0.050 M MaxCalix, 0.50 M Cs-7SB modifier, and 0.0030 M guanidine as indicated, in Isopar L diluent. The O:A ratios were 1:1 for each contact. The contact temperature was maintained at $10 \pm 1$ ${ }^{\circ} \mathrm{C} . \mathrm{N} / \mathrm{O}=$ no emulsion observed.

\subsection{INTERFACIAL TENSION TEST RESULTS}

A series of adapted ESS experiments revealed that the guanidine suppressors depress the interfacial tension under stripping conditions and that the effect depends upon the guanidine structure. Low 
interfacial tensions can serve as an indicator of potential coalescence or other interface-related problems. Given that some conditions for emulsion formation had been identified, albeit at abnormal concentrations of boric acid and guanidine (see above), guanidine interfacial activity was suspected. Thus, an ESS experiment was devised for examination of the variation of interfacial tension of NGCSSX solvent as it is stepped through the ESS sequence for each of the different guanidine candidates. As shown in Table 9, the guanidines have no detectable interfacial activity vs the control solvent without guanidine under the alkaline conditions of extraction and scrubbing. However, the guanidines behave differently under stripping conditions. The differences range from almost no effect (BiTABG), to moderate decrease of interfacial tension (DCiTG and TiDG), to a large decrease in interfacial tension ( $\mathrm{TnDG}_{\mathrm{M}}$ and TnDDG). As a reference point ${ }^{[5]}$, the CSSX solvent gave the following interfacial tensions for extraction, scrubbing, and stripping conditions, respectively (dyne/cm): 18.8, 16.1, and 15.2. The CSSX solvent tested contained only $1 \mathrm{mM}$ TOA, and the aqueous strip solution was $1 \mathrm{mM}$ nitric acid. It appears that the straight-chain structure of $\mathrm{TnDG}_{\mathrm{M}}$ and $\mathrm{TnDDG}$ produces greater interfacial activity under NG-CSSX conditions.

Table 9. Interfacial Tension of Candidate NG-CSSX Solvents Under ESS Conditions ${ }^{a}$

\begin{tabular}{llllcll}
\hline \multicolumn{1}{c}{ Stage } & $\begin{array}{l}\text { Control } \\
\text { No Gua }\end{array}$ & DCiTG & TiDG & TnDG $_{\mathbf{M}}$ & TnDDG & BiTABG \\
\hline Extract & $18.0(4)$ & $18.3(6)$ & $18.2(3)$ & $18.2(3)$ & $19.0(4)$ & $19(1)$ \\
Scrub & $16.0(4)$ & $15(1)$ & $15(1)$ & $16.8(3)$ & $16.8(3)$ & $17.7(6)$ \\
Strip & $16.3(6)$ & $10.8(8)$ & $9.7(3)$ & $6.0(4)$ & $5.33(3)$ & $15.2(3)$ \\
\hline
\end{tabular}

${ }^{a}$ The aqueous phases were SRS-15 waste simulant for extractions, $0.025 \mathrm{M} \mathrm{NaOH}$ for scrubs, and $0.01 \mathrm{M}$ boric acid for strips. Solvents consisted of $0.050 \mathrm{M}$ MaxCalix, $0.50 \mathrm{M}$ Cs-7SB modifier, and $0.0030 \mathrm{M}$ guanidine as indicated, in Isopar L diluent. The O:A ratios were 1:4 for extraction and 3.75:1 for both scrubbing and stripping stages. The precontact temperature was maintained at $25.0 \pm 0.5{ }^{\circ} \mathrm{C}$. Interfacial tension measurements were performed at room temperature, measured at $24.5 \pm 0.5{ }^{\circ} \mathrm{C}$. Units are dyne $\mathrm{cm}^{-1}$. The deviation of duplicate determinations is shown in parentheses, unless the duplicates agreed exactly, in which case the average deviation $\left( \pm 0.4\right.$ dyne $\left.\mathrm{cm}^{-1}\right)$ is given.

\subsection{DISPERSION NUMBERS}

Dispersion numbers as a measure of coalescence rate indicated no particular differences among the four guanidines tested, DCiTG, TiDG, TnDDG, and BiTABG. While no simple test reliably predicts contactor performance, the dispersion number derived from simple break times serves as a rough indicator of behavior, allowing one to categorize performance as poor to excellent ${ }^{[21,23]}$. As such, dispersion numbers serve as an operational indicator for making systematic comparisons ${ }^{[24]}$. Table 10 summarizes the results of an ESS style experiment in which the break times $t_{\mathrm{B}}$ were measured for each step for NG-CSSX solvent with the different guanidines. The dispersion number $N_{\text {Di }}$ was calculated according to Eq. 3. All extraction contacts exhibited "very good" phase disengagement $\left(N_{\mathrm{Di}}=8-16 \times\right.$ 
$\left.10^{-4}\right)$. All scrub contacts exhibited "good" phase disengagement $\left(N_{\mathrm{Di}}=4-8 \times 10^{-4}\right)$. The first two strip contacts ranged from "good" to "very good," while the third and fourth strips were "good." Within the variability of the results, it is judged that the guanidines do not exhibit noticeable differences in coalescence behavior. Whatever differences exist among the guanidines with regard to interfacial tension, particularly under stripping conditions, apparently are not reflected in differences in dispersion number. This is somewhat surprising for TnDDG, whose interfacial tension under stripping conditions was potentially problematic. 
Table 10. Dispersion Numbers for Various Guanidine Suppressors ${ }^{a}$

\begin{tabular}{|c|c|c|c|c|c|c|c|c|}
\hline \multirow[t]{2}{*}{ Stage } & \multicolumn{2}{|c|}{ DCiTG } & \multicolumn{2}{|c|}{ TiDG } & \multicolumn{2}{|c|}{ TnDDG } & \multicolumn{2}{|c|}{ BiTABG } \\
\hline & Avg. $t_{\mathrm{b}}, \mathrm{s}$ & $N_{\mathrm{Di}}$ & Avg. $t_{\mathrm{b}}, \mathrm{s}$ & $N_{\mathrm{Di}}$ & Avg. $t_{\mathrm{b}}, \mathrm{s}$ & $N_{\mathrm{Di}}$ & Avg. $t_{\mathrm{b}}, \mathrm{s}$ & $N_{\mathrm{Di}}$ \\
\hline Extract 1 & $100(2)$ & $1.08(2) \times 10^{-3}$ & $110(2)$ & $9.8(2) \times 10^{-4}$ & $76(3)$ & $1.42(6) \times 10^{-3}$ & $95(3)$ & $1.13(4) \times 10^{-3}$ \\
\hline Extract 2 & $115(6)$ & $9.4(5) \times 10^{-4}$ & $84(2)$ & $1.28(3) \times 10^{-3}$ & $92(2)$ & $1.17(3) \times 10^{-3}$ & $110(2)$ & $9.8(1) \times 10^{-4}$ \\
\hline Scrub 1 & $167(13)$ & $5.8(4) \times 10^{-4}$ & $127(4)$ & $7.6(2) \times 10^{-4}$ & $119(10)$ & $8.0(7) \times 10^{-4}$ & $126(4)$ & $7.6(2) \times 10^{-4}$ \\
\hline Scrub 2 & $195(18)$ & $5.0(5) \times 10^{-4}$ & $160(13)$ & $6.0(5) \times 10^{-4}$ & $138(12)$ & $7.1(6) \times 10^{-4}$ & $144(5)$ & $6.7(2) \times 10^{-4}$ \\
\hline Strip 1 & $102(11)$ & $9.5(10) \times 10^{-4}$ & $107(12)$ & $9(1) \times 10^{-4}$ & $149(5)$ & $6.5(2) \times 10^{-4}$ & $91(3)$ & $1.03(3) \times 10^{-3}$ \\
\hline Strip 2 & $122(3)$ & $8.0(2) \times 10^{-4}$ & $137(5)$ & $7.0(2) \times 10^{-4}$ & $178(6)$ & $5.4(2) \times 10^{-4}$ & $149(3)$ & $6.5(1) \times 10^{-4}$ \\
\hline Strip 3 & $167(14)$ & $5.8(5) \times 10^{-4}$ & $172(8)$ & $5.6(2) \times 10^{-4}$ & $178(5)$ & $5.4(2) \times 10^{-4}$ & $144(4)$ & $6.7(2) \times 10^{-4}$ \\
\hline Strip 4 & $153(8)$ & $6.4(3) \times 10^{-4}$ & $167(1)$ & $5.78(5) \times 10^{-4}$ & $162(10)$ & $5.9(4) \times 10^{-4}$ & $149(1)$ & $6.44(5) \times 10^{-4}$ \\
\hline
\end{tabular}

${ }^{a}$ The aqueous phases were SRS-15 waste simulant for extraction, $0.025 \mathrm{M}$ sodium hydroxide for scrubs, and $0.01 \mathrm{M}$ boric acid for strips. Solvents consisted of $0.050 \mathrm{M}$ MaxCalix, $0.50 \mathrm{M}$ Cs-7SB modifier, and $0.0030 \mathrm{M}$ guanidine as indicated, in Isopar L diluent. The O:A ratios were 1:4 for extraction and 3.75:1 for both scrubbing and stripping stages. Two extractions were carried out due to limited simulant (SRS-15) then the solvent phases were combined for the scrubbing and stripping stages. 


\subsubsection{Thermal Stability Test}

We report here preliminary results of a test of the NG-CSSX solvent containing TiDG suppressor in sustained contact with SRS-15 simulant at $36.0 \pm 0.5{ }^{\circ} \mathrm{C}$ for one month. In previous work with DCiTG $^{[16]}$, the alkaline conditions of extraction and scrubbing were found to be more severe than stripping conditions using $10 \mathrm{mM}$ boric acid with regard to deterioration of ESS performance. Given the choice of TiDG as recommended suppressor for NGS in this work, it was judged prudent to confirm that NGS solvent with TiDG has comparable thermal stability to solvent with DCiTG, considered to be in contact with SRS-15. Owing to the temperature control used in the MCU, the maximum temperature expected under alkaline conditions of extraction and scrubbing is expected to be $26{ }^{\circ} \mathrm{C}$; the extraction section in the MCU is held to $23 \pm 3{ }^{\circ} \mathrm{C}$, and the scrub section, which receives the cool solvent, is not

expected to exceed $26{ }^{\circ} \mathrm{C}{ }^{[25]}$. Thus, the results of this test are considered to correspond to off-normal conditions (beyond worst case).

The test results are shown in Table 11. The samples at 0 and 1 month represent the thermal test samples at the initial and first sampling. The control corresponds to untreated solvent held at room temperature with no aqueous phase present. While the 0 month and control samples appear normal in behavior, it may be seen that the thermal TiDG sample exhibits a lower-than-normal $D_{\mathrm{Cs}}$ value for extraction and a higherthan-normal $D_{\mathrm{Cs}}$ value on the first strip (see Table 4 for typical $D_{C s}$ values in ESS testing.) The extraction $D_{\mathrm{Cs}}$ value returns to normal on the second extraction step. For comparison, the results for a comparable thermal test of the analogous NG-CSSX solvent containing the DCiTG suppressor ${ }^{[16]}$ are shown in Table 11. In that test, the ESS measurements were taken after the thermally treated solvent had been run through the remainder of the first ESS sequence. It may be seen that thermally treated TiDG and DCiTG behave similarly in scrubbing and stripping. Overall, while stripping performance degrades with thermal treatment in both cases, the ESS behavior of solvents containing either suppressor remains excellent over the course of a month of treatment. 
Table 11. Cesium Distribution Ratios for ESS Batch Tests for Thermally Treated Solvents Containing TiDG and DCiTG ${ }^{a}$

\begin{tabular}{|c|c|c|c|c|c|c|}
\hline Stage & $\begin{array}{c}\text { TiDG } \\
\text { 0 Months }\end{array}$ & $\begin{array}{l}\text { TiDG } \\
1 \text { Month } \\
\text { Control }\end{array}$ & $\begin{array}{c}\text { TiDG } \\
1 \text { Month } \\
\text { Thermal }\end{array}$ & $\begin{array}{l}\text { DCiTG }{ }^{[16]} \\
\text { 0 Months }\end{array}$ & $\begin{array}{l}\text { DCiTG }^{[16]} \\
\text { Month } \\
\text { Control } \\
\end{array}$ & $\begin{array}{l}\text { DCiTG }^{[16]} \\
1 \text { Month } \\
\text { Thermal }\end{array}$ \\
\hline Extract 1 & $58.5(7)$ & $68.2(7)$ & $35.9(7)$ & $60.0(6)$ & & \\
\hline Scrub 1 & $3.76(8)$ & $3.22(4)$ & $4.21(4)$ & $2.8(2)$ & & \\
\hline Scrub 2 & $1.18(7)$ & $1.09(7)$ & $1.26(7)$ & $1.01(3)$ & & \\
\hline Strip 1 & $2.00(4) \times 10^{-3}$ & $1.53(4) \times 10^{-3}$ & $1.14(5) \times 10^{-2}$ & $1.3(1) \times 10-^{3}$ & & \\
\hline Strip 2 & $3.71(3) \times 10^{-4}$ & $2.87(3) \times 10^{-4}$ & $4.07(4) \times 10^{-3}$ & $2.1(8) \times 10^{-4}$ & & \\
\hline Strip 3 & $1.87(6) \times 10^{-2}$ & $4.23(3) \times 10^{-4}$ & $4.88(2) \times 10^{-3}$ & $1.5(2) \times 10^{-4}$ & & \\
\hline Extract 2 & $57.3(7)$ & $49.7(7)$ & $50.2(7)$ & & $55(1)$ & $74(5)$ \\
\hline Scrub 1 & & & & & $2.7(4)$ & $4.2(3)$ \\
\hline Scrub 2 & & & & & $0.93(5)$ & $1.89(5)$ \\
\hline Strip 1 & & & & & $1.25(3) \times 10^{-3}$ & $1.12(2) \times 10^{-2}$ \\
\hline Strip 2 & & & & & $4.3(5) \times 10^{-4}$ & $2.5(3) \times 10^{-3}$ \\
\hline Strip 3 & & & & & $2(2) \times 10^{-4}$ & $9(3) \times 10^{-4}$ \\
\hline \multicolumn{7}{|c|}{$\begin{array}{l}{ }^{a} \text { The aqueous phases were SRS- } 15 \text { waste simulant for extraction, } 0.025 \mathrm{M} \mathrm{NaOH} \text { for the scrub stages, and } 0.01 \mathrm{M} \\
\mathrm{H}_{3} \mathrm{BO}_{3} \text { for the strip stages. Solvents consisted of } 0.050 \mathrm{M} \text { MaxCalix, } 0.50 \mathrm{M} \text { Cs- } 7 \mathrm{SB} \text { modifier, and } 0.0030 \mathrm{M} \\
\text { guanidine as indicated, in Isopar L diluent. The O:A ratios were } 1: 4 \text { for extraction and } 3.75: 1 \text { for both scrubbing } \\
\text { and stripping. ESS measurements were carried out at a constant temperature of } 25.0 \pm 0.5{ }^{\circ} \mathrm{C} \text {. Samples marked "0 } \\
\text { Months" were run at the outset of the experiment, with no thermal treatment. Samples marked "Control" were from } \\
\text { the original batch of solvent held at room temperature not in contact with an aqueous phase. Thermal samples were } \\
\text { treated in contact with SRS- } 15 \text { simulant at an O:A ratio of } 1: 4 \text { at nominally } 35^{\circ} \mathrm{C} \text {. }\end{array}$} \\
\hline
\end{tabular}





\section{CONCLUSIONS}

Two new guanidines, TiDG and BiTABG, tested as candidate suppressors for the NG-CSSX process possess superior lipophilicity $\left(P_{\text {Gua }}>1000\right)$ over the control suppressor DCiTG $(P=30)$ and otherwise perform well with regard to essential properties, including ESS, resistance to third-phase formation, resistance to emulsion formation, interfacial tension, and coalescence (dispersion number). Assuming loss to the strip solution is the major loss pathway for the guanidine suppressor, the concentration of both TiDG and BiTABG would be expected to be reduced to half the initial value of $3 \mathrm{mM}$ after more than 2600 solvent cycles, compared with 78 solvent cycles for DCiTG. The reduced loss rate translates to reduced costs of solvent monitoring and reduced risk of process upset. An additional benefit of higher guanidine lipophilicity is more than an order-of-magnitude lower organic concentration in the effluent stream going to the downstream vitrification facility (Defense Waste Processing Facility). For DCiTG, the partition ratio of 30 at an O:A ratio of 3.75:1 implies that the strip effluent will contain 40 ppm of guanidine, as compared with $<1.4 \mathrm{ppm}$ for TiDG or $<1.7 \mathrm{ppm}$ for BiTABG.

Minor considerations lead to TiDG as the preferred choice vs BiTABG. First, in having all alkyl substituents, TiDG is chemically more similar to the reference guanidine DCiTG than is the aromatic BiTABG. In particular, the benzylic hydrogens (the hydrogen atoms of the $\mathrm{CH}_{2}$ group between the benzene ring and the nitrogen atom) of BiTABG are likely more reactive than those in alkyl chains, potentially increasing the degradation rate. Thus, given the information presently available, TiDG is therefore judged somewhat more predictable with regards to stability, interfacial, and phase behavior. Second, the cost of TiDG in bulk is expected to be approximately half that of BiTABG while being comparable to, or slightly greater than, that of DCiTG ${ }^{[26]}$. On the other hand, the cost of even BiTABG would be less than $1 \%$ of the cost of the solvent and therefore not a decisive criterion. Third, TiDG is symmetrical and therefore not expected to exhibit the alkyl scrambling observed upon purification of DCiTG $^{[14]}$. Analytical difficulty is comparable, as BiTABG was not found to be more easily detected by HPLC than TiDG ${ }^{[27]}$. BiTABG yields a higher (better) interfacial tension under stripping conditions than does TiDG (which is comparable to that of DCiTG), but no difference in coalescence behavior could be detected for solvents with any of the tested guanidines. Preliminary test results suggest that TiDG has thermal stability comparable to DCiTG, though testing is incomplete. These factors lead us to recommend TiDG as the most reliable choice of suppressor for the NGS.

Overall, five lipophilic guanidines were tested as candidate suppressors in comparison with DCiTG. One aromatic candidate, TsBPG, failed to function as a suppressor in stripping and was quickly eliminated 
from consideration. Two straight-chain candidates, TnDG and TnDDG, yielded lower-than-expected partition ratios for NG-CSSX solvent in contact with $10 \mathrm{mM}$ boric acid stripping solution. They also yielded low interfacial tensions for NG-CSSX solvent in contact with $10 \mathrm{mM}$ boric acid stripping solution. The process of elimination left TiDG and BiTABG as candidates for selection, which was described above.

The tests allow several observations regarding the behavior of the suppressor candidates. First, the alkyl guanidines DCiTG, TnDG, TiDG, and TnDDG all exhibit comparable ESS behavior even when stressed with surfactant. Also, interfacial behavior as reflected in dispersion numbers (coalescence) and emulsion formation revealed no differences. However, interfacial tensions for the straight-chain suppressors TnDG and TnDDG for the case of solvent in contact with boric acid stripping solution were significantly low compared with DCiTG, TiDG, and BiTABG. While the low interfacial tensions apparently did not lead to problems in the coalescence or emulsion-formation tests, they did correlate with observations of cloudiness in initial solvent washing and with lower-than-expected partition ratios for TnDG and TnDDG under stripping conditions.

Although we have covered what we consider to be the key risks in replacing DCiTG, further testing is planned, focusing on the behavior of NGS with the new suppressor TiDG. An outstanding need that will be addressed is to confirm the functionality of the wash section in removing the traces of 4-secbutylphenol formed as a result of slow breakdown of the Cs-7SB modifier. Since the mechanism by which the suppressor operates in ensuring good stripping is still not understood, experiments are planned to probe its chemical form in the solvent under stripping conditions. Further work will be conducted to investigate the interfacial behavior of the NGS under varying conditions. While it appears that there are no particular issues regarding stability, it would be desirable to test the stability of the solvent under storage after an alkaline wash. Since the solvent hold tank can be expected to have sustained temperatures of $33 \pm 3{ }^{\circ} \mathrm{C}$, knowledge of the rate and nature of degradation of the solvent under simple holding conditions could be used to reduce risk, particularly on startup after extended outages.

\section{ACKNOWLEDGMENTS}

This research was sponsored by the Office of Technology Innovation and Development, Office of Environmental Management, U.S. Department of Energy. The authors are very grateful to Peter Bonnesen for the careful review of this report and for helpful suggestions. 


\section{REFERENCES}

1 Moyer, B. A.; Bonnesen, P. V.; Delmau, L. H.; Sloop, Jr., F. V.; Williams, N. J., Birdwell, Jr., J. F.; Lee, D. L.; Leonard, R. A.; Fink, S. D.; Peters, T. B.; Geeting, M. W. "Development of the NextGeneration Caustic-Side Solvent Extraction (NG-CSSX) Process for Cesium Removal from HighLevel Tank Waste-11346". Proceedings Waste Management 2011 Conference, February 27-March 3, 2011, Phoenix, AZ; Waste Management Symposia, Tempe, AZ, Paper 11346 (2011).

2 Delmau, L. H.; Birdwell, Jr., J. F.; Bonnesen, P. V.; Ladd, C. J.; Moyer, B. A.; Stoner, E. L.; Lee, D. L.; Sloop, Jr., F. V. "Next-Generation Caustic-Side Solvent Extraction (NG-CSSX) Process." Proc. International Solvent Extraction Conference ISEC 2011, Oct. 3-7, 2011, Santiago, Chile; Valenzuela F., Moyer, B. A., Eds.; Gecamin: Santiago, 2011.

3 B. A. Moyer, J. F. Birdwell, Jr., P. V. Bonnesen, Delmau, L. H. "Use of Macrocycles in Nuclear-Waste Cleanup: A Real-World Application of a Calixcrown in Technology for the Separation of Cesium." In Macrocyclic Chemistry-Current Trends and Future, K. Gloe, Ed., Springer, Dordrecht, pp. 383-405 (2005).

4 B. A. Moyer, Alexandratos, S. D.; Bonnesen, P. V.; Brown, G. M.; Caton, Jr., J. E.; Delmau, L. H.; Duchemin, C. R.; Haverlock, T. J.; Levitskaia, T. G.; Maskarinec, M. P.; F. V. Sloop, Jr., F. V.; Stine, C. L. "Caustic-Side Solvent Extraction Chemical and Physical Properties: Progress in FY 2000 and FY 2001." ORNL/TM-2001/285, Oak Ridge National Laboratory, Oak Ridge, TN, 2002.

5 Delmau, L. H.; Birdwell, Jr., J. F.; Bonnesen, P. V.; Foote, L. J.; Haverlock, T. J.; Klatt, L. N.; Lee, D. D.; Leonard, R. A.; Levitskaia, T. G.; Maskarinec, M. P.; Moyer, B. A.; Sloop, Jr., F. V.; Tomkins, B. A. "Caustic-Side Solvent Extraction: Chemical and Physical Properties of the Optimized Solvent.” ORNL/TM-2002/190, Oak Ridge National Laboratory, Oak Ridge, TN (2002).

6 Moyer, B. A.; Birdwell, J. F., Jr.; Delmau, L. H.; McFarlane, J. "Caustic-Side Solvent Extraction Modeling for Hanford Interim Waste Pretreatment System.” Report ORNL/TM-2008/073, Oak Ridge National Laboratory, Oak Ridge, TN, June 2008.

7 Delmau, L. H.; Haverlock, T. J.; Bazelaire, E.; Bonnesen, P. V.; Ditto, M. E.; Moyer, B. A. "Alternatives to Nitric Acid Stripping in the Caustic-Side Solvent Extraction (CSSX) Process for Cesium Removal from High-Level Waste." Solvent Extr. Ion Exch. 2009, 27, 172-198.

8 Delmau, L. H.; Birdwell, Jr., J. F.; McFarlane, J.; Moyer, B. A. "Robustness of the CSSX Process to Feed Variation: Efficient Cesium Removal from the High Potassium Wastes at Hanford." Solvent Extr. Ion Exch. 2010, 28, 19-48.

9 Peters, T. B.; Poirier, M. R.; Nash, C. A.; Fondeur, F. F.; Fink, S. D.; Brown, S. J.; Brass, E. A.“Testing and Startup of the Savannah River Site Integrated Salt Disposition Process." Paper 9193, Proc. Waste Management 2009 (WM '09), Phoenix, AZ, Mar. 1-5, 2009, Waste Management Symposia, Tempe, AZ (2009).

10 Brown, S. J. "Caustic Side Solvent Extraction at the Savannah River Site: Operating Experience and Lessons Learned." Paper 10105, Proc. Waste Management 2010 (WM '10), Phoenix, AZ, Mar. $7-$ 11, 2010, Waste Management Symposia, Tempe, AZ (2010).

11 Peters, T. B.; Poirier, M. R.; Fondeur, F. F.; Fink, S. D.; Brown, S. J.; Geeting, M. W. "Operations Review of the Savannah River Site Integrated Salt Disposition Process." Paper 11327, Proc. Waste Management 2011 (WM '11), Phoenix, AZ, Mar. 1-5, 2011, Waste Management Symposia, Tempe, AZ (2011).

12 Duncan, N. C.; Roach, B. D.; Williams, N. J.; Bonnesen, P. V.; Rajbanshi, A.; Moyer, B. A. 'N,N'Dicyclohexyl-N'-Isotridecylguanidine as Suppressor for the Next Generation Caustic-Side Solvent Extraction (NG-CSSX) Process.” Sep. Sci. Technol. 2012, 47, 2074-2087.

13 Peters, T. B.; Fink, S. D. "Results of the First Extraction-Scrub-Strip Testing Using Improved Solvent Formulations and Actual Savannah River Site Waste." SRNL-STI-2010-00586, Savannah River National Laboratory, Aiken, SC (2010). 
14 Pierce, R. A.; Peters, T. B.; Crowder, M. L.; Caldwell, T. D.; Pak, D. J.; Fink, S. D.; Blessing, R. W.; Washington, A. L. "Demonstration of the Next-Generation Caustic-Side Solvent Extraction Solvent with 2-cm Centrifugal Contactors using Tan 49H waste and Waste Simulant." SRNL-STI-201100589, Savannah River National Laboratory, Aiken, SC (2011).

15 Birdwell, J. F.; Lee, D. L. "Property Determinations and Preliminary Engineering Evaluation of Next Generation CSSX Processing." ORNL-LTR-NGCSSX-004, Oak Ridge National Laboratory, Oak Ridge, TN, December 30, 2010.

16 Williams, N. J.; Roach, B. D.; Moyer, B. A.; Lee, D. L. "Effect of Radiolytic and Thermal Treatment on the Performance of the Next-Generation Caustic-Side Solvent Extraction (NG-CSSX) Solvent." ORNL-LTR-NGCSSX-017, Oak Ridge National Laboratory, Oak Ridge, TN, September 30, 2011.

17 Wittekind, R. R.; Capiris, T.; Fahey, J.; Shavel, J., Jr., "1-(2-Imidazolin-2-yl)-2-imidazolines. I. The Structure of Jaffe's Base and the Chemistry of Related Compounds." J. Org. Chem. 1973, 38, $1641-1645$.

18 Briody, T. A.; Hegarty, A. F.; Scott, F. L. "Elimination-Addidition Mechanism for Base Catalysed Conversion of S-Alkylthioureas to Ureas." Tetrahedron 1977, 33, 1469-1474.

19 Chicharro, J.-L.; Prados, P.; de Mendoza, J. "Synthesis and Self Association of 4,7-Diamino-2,9dimethyl-5,6,11a-triaza-6,11,11a,12-tetrahydronaphthacene Derivatives as Dibenzoguanidine Receptors for Oxoanion Recognition.” J. Chem. Soc., Chem. Commun. 1994, 1193-1194.

20 Peterson, R. A., "Preparation of Simulated Waste Solutions for Solvent Extraction Testing, WSRCRP-2000-00361.” Rev. 0, Westinghouse Savannah River Company, Aiken, South Carolina, May 2000.

21 du Nouy, P. L., "An Interfacial Tensiometer for Universal Use." J. Gen. Phys., 1925, 7, 625-633.

22 Leonard, R. A., "Solvent Characterization Using the Dispersion Number." Sep. Sci. Technol. 1995, 30, $1103-1122$.

23 Roach, B. D.; Williams N. J., unpublished results (manuscript in preparation).

24 Leonard, R. A. "Design rules for solvent extraction." Solvent Extr. Ion Exch. 1999, 17, 597-612.

25 R. D. Lentsch, A. B. Stephens, K. E. Bartling, and S. A. Singer, "Caustic-Side Solvent Extraction FullScale Test," Paper 8431, Proc. Waste Management 2008, Feb. 24-28, 2008, Phoenix, AZ; Waste Management Symposia, Tempe, AZ (2008).

26 Foster, M., Marshallton Research Labs, Inc., Tobaccoville, NC, personal communication, September 4, 2012.

27 Brugh, M. S., Parsons Engineering, Aiken, SC, teleconference, Dec. 6, 2012. 